\title{
Molecular, Topographic, and Functional Organization of the Cerebellar Nuclei: Analysis by Three-Dimensional Mapping of the Olivonuclear Projection and Aldolase C Labeling
}

\author{
Izumi Sugihara and Yoshikazu Shinoda \\ Department of Systems Neurophysiology, Tokyo Medical and Dental University Graduate School of Medicine, Tokyo 113-8519, Japan
}

The olivocerebellar climbing fiber projection pattern is closely correlated with the pattern of aldolase C expression in cerebellar Purkinje cells. Based on this expression pattern, the olivocerebellar projection can be classified into five "groups" of functional compartments. Each group originates from a subarea within the inferior olive that projects to multiple cortical stripes of Purkinje cells, all of which are either aldolase $\mathrm{C}$ positive or aldolase $\mathrm{C}$ negative. However, no equivalent compartmental organization has been demonstrated in the cerebellar nuclei $(\mathrm{CN})$. Thus, in the $\mathrm{CN}$ of the rat, we systematically mapped the location of olivonuclear projections belonging to the five groups and determined their relationship to the expression of aldolase $\mathrm{C}$ in Purkinje cell axonal terminals.

The $\mathrm{CN}$ were divided into caudoventral aldolase $\mathrm{C}$-positive and rostrodorsal aldolase $\mathrm{C}$-negative parts. The olivonuclear terminations from the five groups projected topographically to five separate compartments within the $\mathrm{CN}$ that partly crossed the traditional boundaries that define the fastigial, interposed, and dentate nuclei. Each compartment had mostly uniform cytoarchitecture and the same aldolase $\mathrm{C}$ expression (either positive or negative) that was found in the corresponding olivocortical projection. These results suggest a new view of the organization of the $\mathrm{CN}$ whereby the pattern of olivonuclear terminations links portions of different $\mathrm{CN}$ together. We propose that each compartment in the $\mathrm{CN}$, along with its corresponding olivary subarea and cortical stripes, may be related to a different aspect of motor control.

Key words: climbing fiber; inferior olive; aldolase C; zebrin; biotinylated dextran amine; rat

\section{Introduction}

The cerebellar nuclei $(\mathrm{CN})$, the major source of the cerebellar output, are conventionally divided into the fastigial (medial), interposed, and dentate (lateral) nuclei (Brodal, 1981; Voogd, 2004). These divisions, partially separated by the white matter, project to different areas in the brainstem and thalamus and are innervated by Purkinje cells in the conventional three divisions of the cerebellar cortex (i.e., vermis, pars intermedia, and hemisphere). Thus, these subdivisions of the $\mathrm{CN}$ are considered to be functionally distinct.

In the cerebellar cortex, longitudinal compartmentalization beyond the conventional three divisions has been revealed by the demonstration of zones A-D based on cholinesterase labeling in the cerebellar white matter and the topography of the corticonuclear and olivocortical projections (Voogd, 1967; Groenewegen and Voogd, 1977; Buisseret-Delmas and Angaut, 1993). Even

Received April 9, 2007; revised July 19, 2007; accepted July 20, 2007.

This work was supported by Grants-in-Aid for Scientific Research from the Japan Society for the Promotion of Science (18500309 to I.S. and 18300183 to Y.S.), by a Grant-in-Aid for Scientific Research on Priority AreasIntegrative Brain Research from the Ministry of Education, Culture, Sports, Science, and Technology of Japan (18019013 to I.S.), and by a grant from the 21st Century Centers of Excellence Program. We thank Dr. E. J. Lang for reading this manuscript.

Correspondence should be addressed to Dr. Yoshikazu Shinoda, Department of Systems Neurophysiology, Tokyo Medical and Dental University, Graduate School of Medicine, 1-5-45 Yushima, Bunkyo-ku, Tokyo 113-8519, Japan. E-mail:yshinoda.phy1@tmd.ac.jp.

DOI:10.1523/JNEUROSCI.1579-07.2007

Copyright $\odot 2007$ Society for Neuroscience $\quad$ 0270-6474/07/279696-15\$15.00/0 finer longitudinal compartmentalization in the cerebellar cortex is possible based on the expression pattern of aldolase C (zebrin II) (Hawkes and Leclerc, 1987). Recently, several groups have demonstrated a correspondence between the olivocortical projection pattern and aldolase $\mathrm{C}$ compartments of the cerebellar cortex (Voogd et al., 2003; Sugihara and Shinoda, 2004; Voogd and Ruigrok, 2004; Pijpers et al., 2005, 2006). This suggests that molecular expression, olivocortical topography, and functional compartmentalization are integrated within the organization of the cerebellar cortex. Our recent report classified olivocerebellar projections (and aldolase C compartments) into five groups, based on differences in the aldolase $\mathrm{C}$ expression pattern (positive or negative), other morphological characteristics of target aldolase $\mathrm{C}$ compartments, and region of origin within the inferior olive (IO) of olivocerebellar axons (Sugihara and Shinoda, 2004).

The compartmentalization in the cerebellar cortex suggests that an equivalent fine compartmentalization may exist in the $\mathrm{CN}$, because Purkinje cells project topographically onto the $\mathrm{CN}$ (Buisseret-Delmas and Angaut, 1993) and topographically arranged olivocerebellar axons give rise to collaterals to the $\mathrm{CN}$ (Sugihara et al., 1999, 2001). In particular, the compartmentalization in the $\mathrm{CN}$ may be linked to the olivonuclear projection, because the individual axons of this pathway have localized termination areas in the $\mathrm{CN}$ (Sugihara et al., 1999).

In the present study, olivary axons were labeled by a small injection of tracer into various areas of the IO in the rat. In each 
case, we classified the olivocortical projection pattern of the labeled olivary neurons into one of the five groups by mapping labeled climbing fibers within cortical aldolase $\mathrm{C}$ compartments. We then mapped the location of labeled terminals of olivonuclear collaterals that arose from the same labeled olivary neurons within the $\mathrm{CN}$. A new three-dimensional mapping technique was used to facilitate the comparison of the positional relationship among mapped areas, because the positional relationship is not easy to grasp from the conventional maps used in previous studies (Buisseret-Delmas and Angaut, 1993; Ruigrok and Voogd, 2000). Next, the aldolase $C$ expression of Purkinje cell axon terminals was used to map the cortical compartments onto the $\mathrm{CN}$. The localization of the Purkinje terminal aldolase $\mathrm{C}$ labeling was then compared with the compartmental organization of the five groups in the $\mathrm{CN}$ determined by olivonuclear projections.

\section{Materials and Methods}

Tracer injection and histological procedure. Mapping of the olivonuclear termination area was performed in a total of 76 Long-Evans adult rats (Kiwa Laboratory Animals, Wakayama, Japan), which included 48 rats that were used in our previous study on cortical compartmentalization (Sugihara and Shinoda, 2004). All of the experimental animals in this study were treated according to the Guiding Principles for the Care and Use of Animals in the Field of Physiological Sciences of the Physiological society of Japan (2001 and 2002 editions). The experimental protocols were approved by the Institutional Animal Care and Use Committee of Tokyo Medical and Dental University (numbers 0020238, 0030129, 0040089, 0050041, and 0060121). The anesthesia, surgical, and histological procedures were similar to those described previously (Sugihara et al., 1999, 2001).

Briefly, the animals were anesthetized with an intraperitoneal injection of ketamine $(130 \mathrm{mg} / \mathrm{kg}$ body weight $)$ and xylazine $(8 \mathrm{mg} / \mathrm{kg})$. Atropine $(0.4 \mathrm{mg} / \mathrm{kg})$ was also given intraperitoneally. Supplemental doses of ketamine $(13 \mathrm{mg} / \mathrm{kg})$ and xylazine $(1 \mathrm{mg} / \mathrm{kg})$ were given every $30 \mathrm{~min}$ starting $1 \mathrm{~h}$ after the initial dose, as required. Biotinylated dextran amine [BDA; D-1956, 10,000 molecular weight (MW) or D-7135, $3000 \mathrm{MW}$; Invitrogen, Eugene, $\mathrm{OR}]$ was pressure injected at various locations in the IO $(\sim 0.004 \mu \mathrm{l}$ of $10 \%$ solution in saline $)$ for anterograde labeling. Single injections were made in the left and right IO of each animal because the olivocerebellar projection is almost entirely contralateral. The injected tracer spread to a diameter of $0.1-0.2 \mathrm{~mm}$. After a survival period of 6-9 $\mathrm{d}$, the rats were anesthetized in the same way as in the first operation, but with 1.5 times larger dose of ketamine and xylazine. They were perfused intracardially with PBS, followed by fixative containing $5 \%$ paraformaldehyde, $3 \%$ sucrose, and $50 \mathrm{~mm}$ phosphate buffer, $\mathrm{pH}$ 7.4. Eightymicrometer-thick serial frozen sections were cut from the cerebellum and medulla. Horizontal sections were obtained from 11 rats, and coronal sections were cut from 65 rats.

The immunohistological procedures used to double label BDA (black reaction product) and aldolase $\mathrm{C}$ (brown reaction product) with diaminobenzidine have been described previously (Sugihara and Shinoda, 2004). The anti-aldolase $C$ antibody used in this study was raised in our laboratory by immunizing a rabbit with a synthetic peptide that represented amino acids 322-344 from rat aldolase C (Sugihara and Shinoda, 2004). This antibody stains a single band on Western blot analysis with rat cerebellar tissue, and the addition of the immunizing peptide to the primary antibody solution abolishes immunostaining (Sugihara and Shinoda, 2004). Some sections were counterstained with thionine after they were mounted on glass slides.

Six Long-Evans adult rats were used solely for labeling of aldolase $\mathrm{C}$ in the $\mathrm{CN}$. These adult rats were anesthetized, perfused, and fixed in the same way as described above. Serial frozen sections of the cerebellum and medulla were cut in the horizontal, parasagittal, and coronal planes. The immunohistological procedures used to label aldolase $\mathrm{C}$ black with diaminobenzidine have been described previously (Sugihara and Shinoda, 2004). Sections were photographed using a digital camera (DP-50; Olympus, Tokyo, Japan) attached to a microscope (BX41; Olympus).
Photographs were assembled using Photoshop LE software (Adobe Systems, San Jose, CA). The software was used to adjust contrast and brightness, but no digital enhancements were applied.

Mapping nuclear termination areas on the three-dimensional template of the $C N$. To make standardized three-dimensional maps for the $\mathrm{CN}$ of the rat, four Long-Evans adult rats were anesthetized, perfused, and fixed in the same way as described above. In each animal, a cubic block containing the $\mathrm{CN}$ was dissected from the cerebellum and medulla. The block was embedded in gelatin, and coronal, parasagittal, or horizontal 40$\mu \mathrm{m}$-thick frozen serial sections were cut. The sections were mounted and stained with thionine. The outlines of the $\mathrm{CN}$ and adjacent structures were depicted in every section with a camera lucida to make our own atlas of the $\mathrm{CN}$ in coronal, parasagittal, and horizontal planes in these rats. These outlines were digitized using two-dimensional graphics software (Illustrator; Adobe Systems). The outlines in serial sections were drawn in different "layers" of the software. The positions and tilts of the drawings of serial sections were adjusted so that all sections fit each other when superimposed. The Illustrator graphic files were then imported into three-dimensional graphics software (Rhinoceros; Robert McNeel \& Associates, Seattle, WA). Outlines in different sections were shifted in the direction of the $z$-axis by a distance equivalent to the thickness of the section to reconstruct the $\mathrm{CN}$ in the three-dimensional space of the software. The three images of the reconstructed $\mathrm{CN}$ based on the coronal, parasagittal, and horizontal sections were superimposed on each other in the software. Slight adjustments (magnification, rotation, shearing, shifting) were made to the images to obtain the best fit among the three images of the $\mathrm{CN}$. We took this final image to be an optimum, standardized three-dimensional image of the $\mathrm{CN}$, which we then used for mapping terminal locations.

To map the terminations (swellings) of olivocerebellar projection within the $\mathrm{CN}$, the following procedure was followed. When a histological section contained labeled terminals, its relative position within the $\mathrm{CN}$ was determined. For coronal sections, the most caudal part of the posterior interposed nucleus (PIN) and the most rostral part of the anterior interposed nucleus (AIN) were used to mark the limits of the $\mathrm{CN}$, and the distance of the section from these limits defined its relative position. The dorsal pole of the dorsolateral protuberance (DLP) and the most rostral corner of the fourth ventricle were used for the same purpose for horizontal sections. The sections corresponding to the relative position and adjacent positions in the standardized $\mathrm{CN}$ were displayed on the computer monitor. The histological section was superimposed on these standard sections by using a camera lucida apparatus attached to the microscope, and the standardized section that gave the best fit for a given section was selected and defined the position of histological section. Higher magnifications were then used in the microscope to see the terminal swellings of the olivocerebellar axons, which were marked on the standardized section that were digitally magnified. The area in which axon terminals were located was carefully circumscribed by drawing a curve within Rhinoceros. The same procedures were repeated for all sections that contained nuclear terminations from the same injection. The "loft" command in Rhinoceros was then used to construct a solid shape that enclosed these terminals and thereby defined the termination region of the labeled axons (see Fig. 2, compare $C, D$ ).

The procedures for mapping injection sites in the horizontal representation of the IO and labeled climbing fibers in the unfolded cerebellar cortex have been described previously (Sugihara and Shinoda, 2004). The subdivisions of the IO have also been described previously (Sugihara and Shinoda, 2004) and were similar to those reported by Ruigrok and Voogd (1990).

In the figures in this paper, all brain drawings for which injections were made into the left IO were reversed about the midline, so that all climbing fibers were plotted in the left cerebellar cortex and nuclei. The anatomical terms for the CN corresponded to those used by Voogd (2004) and Ruigrok (2004).

\section{Results}

Aldolase $\mathrm{C}$ compartments in the $\mathrm{CN}$

Aldolase C (zebrin II) is expressed in a population of Purkinje cells that are arranged in a stripe pattern in the cerebellar cortex 
(Brochu et al., 1990; Ahn et al., 1994). Individual stripes in the anterior and posterior halves of the cerebellar cortex are anatomically related such that each stripe in one half of the cortex pairs with one in the other half to form a compartment. Approximately 24 such pairs (compartments) have been described and have been named by using the number of the anterior stripe followed by the number of the posterior stripe [e.g., "compartment $1+/ / 1+$ "; for details see, Sugihara and Shinoda (2004), their Table 1]. Aldolase $C$ was expressed not only in the somata and dendrites of positively stained Purkinje cells but also in their axons and axonal terminals (Fig. 1C). Labeled axonal bundles of aldolase C-positive Purkinje cells could be traced in serial sections from the cerebellar cortex through the white matter (Fig. $1 A a, A b, B a, B b, B d$, asterisks) to some parts of the $\mathrm{CN}$ where the labeled axons ended in labeled (aldolase C-positive) terminals. In contrast, no neuronal somata or dendrites of neurons in the cerebellar (or vestibular) nuclei were clearly labeled.

Thus, we defined regions of the $\mathrm{CN}$ (and vestibular nuclei) as aldolase $\mathrm{C}$ positive or negative based on the presence or absence of labeled Purkinje axon terminals. If one just considered overall labeling, the distinction or contrast between the aldolase C-positive and -negative areas was less clear than in the cerebellar cortex; however, it was noted that often axons of labeled Purkinje cells may pass through an otherwise unlabeled area without forming terminals. Therefore, we based our definition of positively and negatively stained $\mathrm{CN}$ regions exclusively on terminal labeling. With this criterion, clearly demarcated compartments emerged in the $\mathrm{CN}$.

Parasagittal sections showed that the overall staining pattern in the interposed and fastigial nuclei was positively stained areas located caudoventrally and negatively stained regions located rostrodorsally with a clear boundary in each nucleus

(Fig. 1Aa-Af). In coronal sections, the ventral parts of the $\mathrm{CN}$ were generally aldolase $\mathrm{C}$ positive, consistent with the findings in parasagittal sections.

Regarding individual CN, the fastigial nucleus (FN) was aldolase $\mathrm{C}$ positive in the ventrocaudal portion and aldolase $\mathrm{C}$ negative in the rostrodorsal portion (Fig. $1 A a-A c, B a-B d$ ). The DLP was aldolase $C$ negative, except for its caudoventral neck (Fig. $1 B a, D$ ). The interstitial cell group (ICG) (Buisseret-Delmas et al., 1998), which is the most lateral and ventral part of the FN near the PIN, was negative in the dorsal portion and positive in the ventral portion (Fig. $1 A c, B b$ ).

The AIN was generally aldolase $\mathrm{C}$ negative (Fig. $1 A c-A e, B b-B d$ ). The most medial and caudal portion of the AIN, which is called the dorsomedial crest (DMC), stained weakly for aldolase C (Fig. $1 \mathrm{Bb}$ ). However, this area was considered to be the aldolase $\mathrm{C}$ negative in
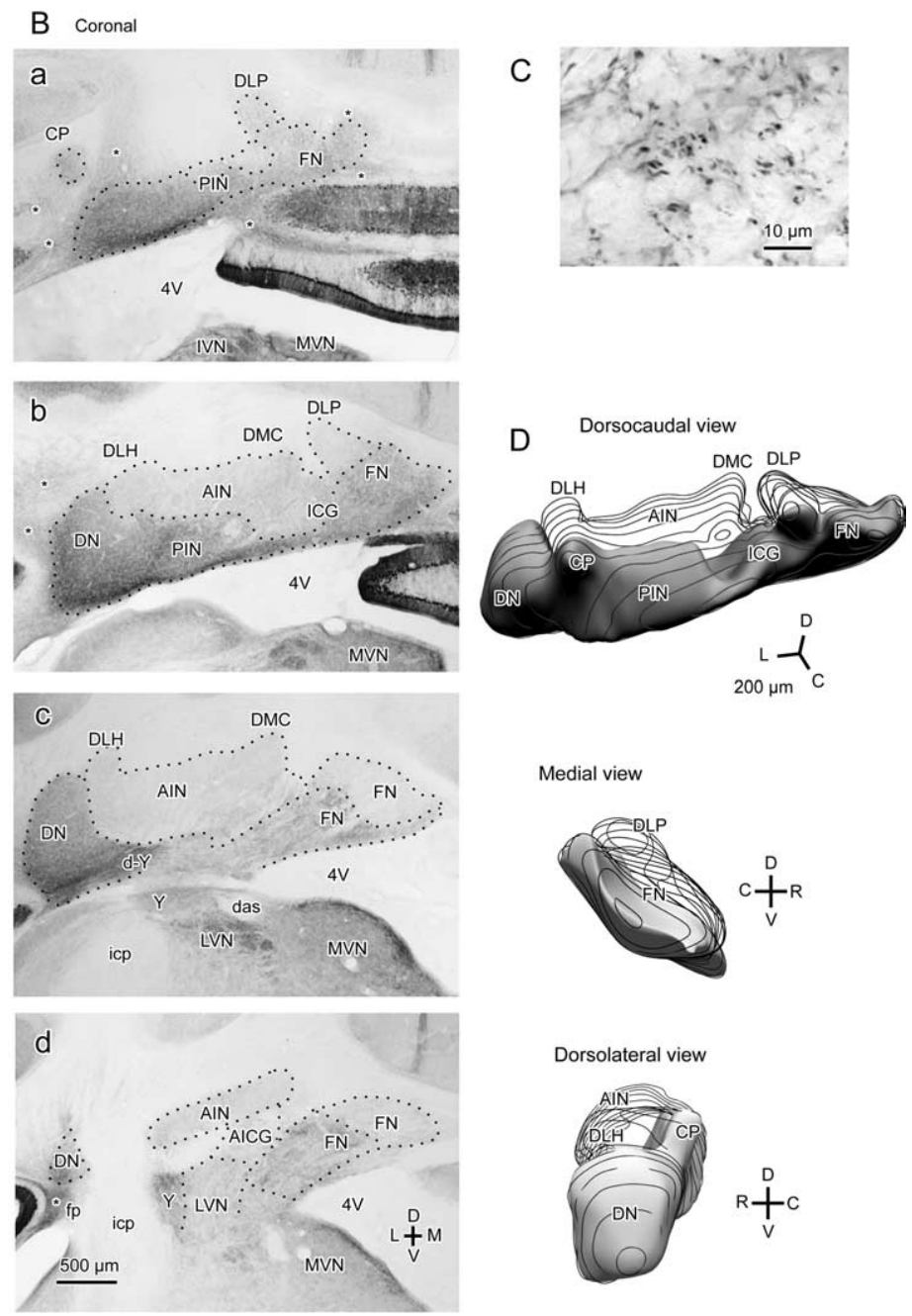

Figure 1. Photomicrographs of aldolase C compartments in the CN. $\boldsymbol{A}, \boldsymbol{B}$, Parasagittal ( $\boldsymbol{A} \boldsymbol{a}-\boldsymbol{A g}$, medial to lateral) and coronal ( $B \boldsymbol{a}-\boldsymbol{B d}$, caudal to rostral) sections of the $\mathrm{CN}$ labeled with anti-aldolase ( antibody. Dotted curves indicate the contour of the $\mathrm{CN}$ (the CN labeled with anti-aldolase C antibody. Dark dots of $\sim 1 \mu \mathrm{m}$ in diameter are terminals ase -positive Purkinje cell axons. D, Three-dimensional reconstruction of the aldolase C-positive area (dark areas) in the fourth ventricle; I-X, lobules I-X; a-d, sublobules a-d or subnuclei a- $c_{\text {; }} B E T A$, subnucleus $\beta ; C_{1} c-$, caudal; Cop, f KOOY: DPFL, dora peduncle; IVN, inferior vestibular nucleus; L, lateral; M, medial; Par, paramedian lobule; pf, primary fissure; R, r-, rostral; Sim simple lobule; V, v-, ventral; VLO, ventrolateral outgrowth; VPFL, ventral paraflocculus.

this study, because the labeling was so weak compared with the other aldolase C-positive areas. The dorsolateral hump (DLH), which protrudes rostrodorsally and usually is considered to be the most lateral part of the AIN, was aldolase C negative (Fig. $1 A f, B c$ ). The caudal pole $(\mathrm{CP})$, which is located caudal to the DLH and protrudes caudally, was aldolase $\mathrm{C}$ positive (Fig. $1 \mathrm{Af}, \mathrm{Ba}$ ). The $\mathrm{CP}$ may be considered to belong to the dentate nucleus (DN; see below, Group I and Discussion).

The PIN was aldolase $\mathrm{C}$ negative in the small dorsomedial portion (Fig. $1 A d, B a$ ) and aldolase $\mathrm{C}$ positive in the rest (Fig. $1 A d, A e, B a, B b)$. Thus, aldolase $\mathrm{C}$ labeling can delineate the boundary between the lateral PIN and the AIN (Fig. 1Ae).

The entire DN was aldolase C positive (Fig. $1 A f, A g, B b, B c$ ). Among the aldolase $\mathrm{C}$-positive areas in the $\mathrm{CN}$, the ventral 


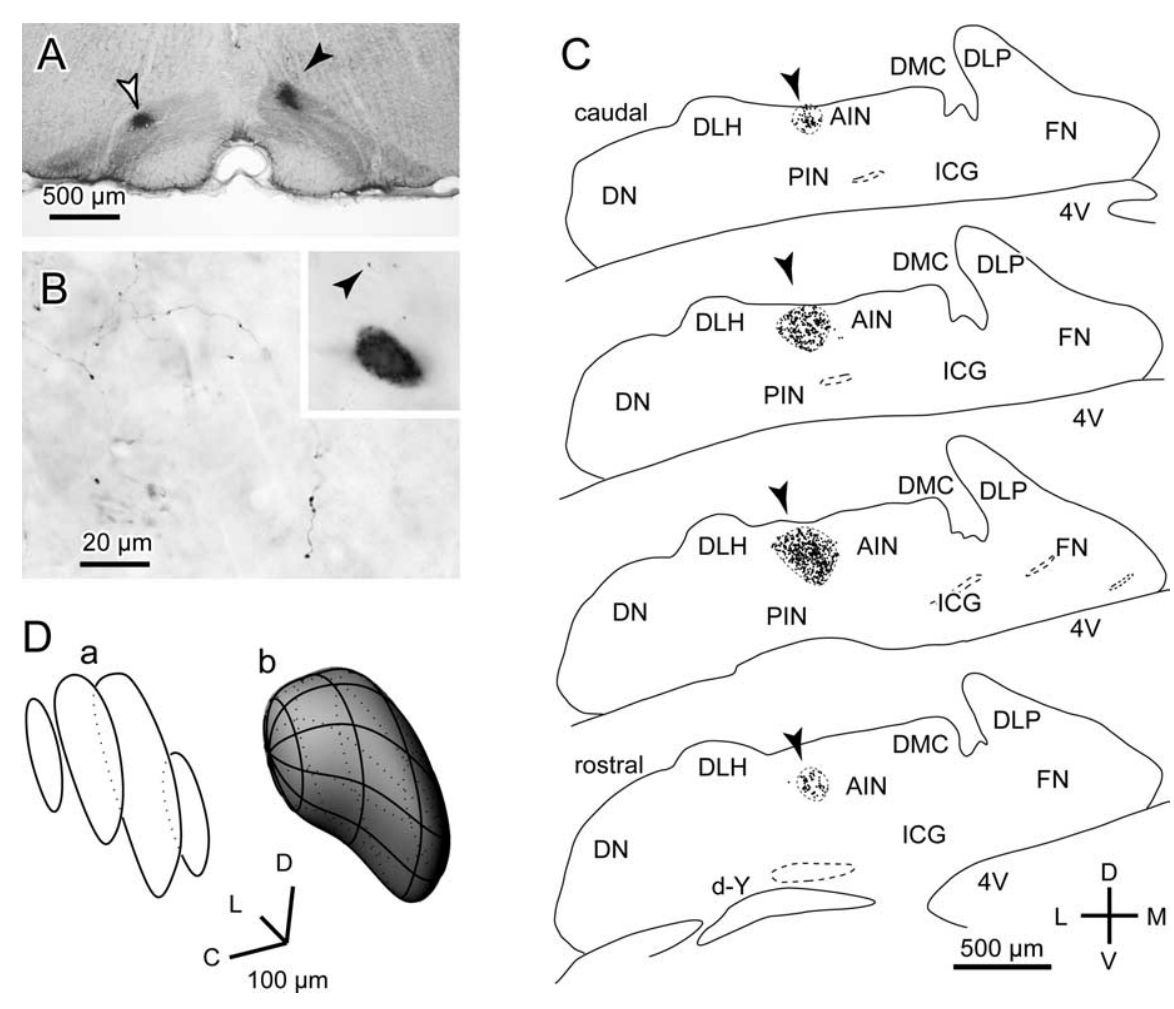

Figure 2. Nuclear termination of the olivocerebellar projection. $\boldsymbol{A}$, Photomicrograph of two bilateral injection sites of BDA (white and black arrowheads) in the I0. The one on the right side (black arrowhead) is the origin for the terminals shown in $\boldsymbol{B}$ and $\boldsymbol{C}$. $\boldsymbol{B}$, Photomicrographs of axonal terminals in a nuclear termination area. Inset, One of the retrogradely labeled neurons in the $\mathrm{CN}_{\text {, }}$ which were seen near the axonal terminals (arrowhead) when the injection was larger. C, Camera lucida drawing of all swellings of axonal terminals in serial sections ( $80 \mu \mathrm{m}$ thick). Their location (arrowheads and dotted curves) was determined under low power ( $4 \times$ objective), and individual swellings were mapped under medium power $(20 \times)$. D, Illustration of the threedimensional mapping of the nuclear termination area. Curves were drawn in three-dimensional software (Rhinoceros) to circumscribe most of the swellings in serial sections (a). The loft command of Rhinoceros was used to form a three-dimensional closed surface that represents the entire termination area (b).

$\mathrm{DN}$ and ventral PIN were the most densely labeled (Fig. $1 A d-A g, B a-B c)$.

We also analyzed aldolase $\mathrm{C}$ labeling of the vestibular nucleus, some parts of which were innervated by nuclear collaterals of olivocerebellar projection (see the next paragraph). The dorsal Y nucleus (infracerebellar nucleus), which receives the projection of olivocerebellar axons innervating the flocculus (Sugihara et al., 2004), was highly aldolase $\mathrm{C}$ positive (Fig. $1 A e, B c$ ). The group $\mathrm{Y}$ (ventral Y) nucleus was also highly positive (Fig. $1 A e, B c, B d$ ). The superior vestibular nucleus was moderately or weakly aldolase $C$ positive. The medial vestibular nucleus was generally aldolase $\mathrm{C}$ positive, except that its rostral part was less strongly labeled (Fig. $1 B a-B d)$. The superficial area of the medial vestibular nucleus facing the fourth ventricle strongly expressed aldolase $C$ (Fig. $1 B c$ ). The inferior vestibular nucleus and the lateral vestibular nucleus (LVN) usually expressed aldolase $\mathrm{C}$ weakly (Fig. $1 \mathrm{Ba}, \mathrm{B}$ $c, B d)$, probably because of fibers of passage that were aldolase $\mathrm{C}$ positive.

Several patches within the central part of the lateral and inferior vestibular nuclei were strongly aldolase $\mathrm{C}$ positive and seemed to consist of dense bundles of aldolase C-labeled axons that projected to the medial vestibular nucleus (Fig. $1 \mathrm{Bc}$ ). Among all of these vestibular nuclei, an olivary projection has been demonstrated in the dorsal part of the LVN as well as in the dorsal Y nucleus (Ruigrok and Voogd, 2000; Sugihara et al., 2004). Therefore, these two areas of the vestibular nuclei were included in the scheme of the CN used for mapping in this study.

\section{Nuclear termination of} olivocerebellar projection

More than $90 \%$ of olivocerebellar axons have collaterals terminating in the $\mathrm{CN}$ (Sugihara et al., 1999). Collaterals of a single olivocerebellar axon project to a small localized area within a single cerebellar nucleus by making terminal arbors that are much less dense than those of climbing fibers in the cerebellar cortex (Fig. 2B). We first systematically examined the distribution of terminals of nuclear collaterals of olivocerebellar axons in rats (74 injections in 48 rats) in which cortical termination had been analyzed in a previous study (Sugihara and Shinoda, 2004). We later analyzed 49 new injections in 28 rats, in which cortical termination was first mapped on the scheme of aldolase C compartments to identify the projection pattern of olivocerebellar neurons (for example, $1+/ / 1+, 1-/ / 1-$, and so on) as in the previous study (Sugihara and Shinoda, 2004). The relationship between the injection site in the olive (Fig. $2 \mathrm{~A}$ ) and the termination area on the aldolase $\mathrm{C}$ compartments in the cerebellar cortex in these 49 injections confirmed our previous report (Sugihara and Shinoda, 2004).

In most cases ( $n=80$ of 123 injections), labeled climbing fibers were distributed within a single aldolase C compartment. To find the nuclear termination area, a bundle of labeled olivocerebellar axons was traced proximally from the cerebellar cortex toward the cerebellar peduncle. At some point near or inside the $\mathrm{CN}$, several thin collaterals were given off from their stem axons. These thin collaterals ran for variable distances of $<100$ to $>500 \mu \mathrm{m}$ and finally terminated in the $\mathrm{CN}$ by making a sparse arborization with swellings, as reported previously (Sugihara et al., 1999). In some cases $(n=$ 43 of 123 injections), a small number of labeled climbing fibers were distributed in aldolase $\mathrm{C}$ compartments of the cortex that were transversely separate from the main terminating compartment [the "outside projection" of Sugihara and Shinoda (2004)]. The nuclear termination area of axons that terminated in the main target compartment in the cortex was distinguished from that of axons that terminated in the outside compartment by tracing axonal bundles through serial sections in these cases. The outside projection could be interpreted as the expansion of the injection into adjacent areas in the olive, although the possibility of single-axon branching to these separate compartments could not be totally excluded without reconstructing the entire trajectories of single axons. We did not use cases in which the nuclear termination areas for the main and outside projections were indistinguishable in further analysis.

The swellings of traced nuclear collaterals were distributed within a single circular area that was $150-300 \mu \mathrm{m}$ in diameter on individual sections (Fig. 2C). A few swellings were occasionally separated from the main high-density area. When reconstructed in three-dimensional space, however, the nuclear termination area was generally elongated in a certain direction so that it looked cuneiform shaped rather than spherical (Fig. 2D). The 
Table 1. Definition of groups $I-V$ and presumed major input to the 10 of each group

\begin{tabular}{|c|c|c|c|}
\hline Group & 10 & Cerebellar cortex & Major input to the 10 \\
\hline I & $\begin{array}{l}\text { Subnucleus } a \text { of the c-MAO, r-MA0, v-P0 except for } \\
\text { the caudomedial part, d-PO (lateral and rostral I0) }\end{array}$ & $\begin{array}{l}1+/ / 1+, 2+/ / 3+, 4+/ / 5+, 5+/ / 6+, 6+/ / 7+\text { (positive compart- } \\
\text { ments that extend beyond the primary fissure to the anterior lobe) }\end{array}$ & Mesodiencephalic \\
\hline Ila & $\begin{array}{l}\text { Caudal subnucleus c of the c-MA0, } \beta, \text { DMCC, caudal } \\
\text { DM, caudomedial v-PO (medial I0) }\end{array}$ & $\begin{array}{l}a+/ / 2+(V l a, V I I I, I X), 2 b+/ / 4+\text { (positive compartments that do not ex- } \\
\text { tend beyond the primary fissure but are located in the posterior lobe) }\end{array}$ & Vestibular \\
\hline Ilb & $\begin{array}{l}\text { Medial and lateral subnucleus c of the c-MA0 (ventro- } \\
\text { caudomedial I0) }\end{array}$ & $\begin{array}{l}a+/ / 2+(V l b-V I I), c+/ / 4 b+, d+/ / 5 a+\text { (positive compartments that do } \\
\text { not extend beyond the primary fissure but are located in the posterior } \\
\text { lobe) }\end{array}$ & Collicular \\
\hline III & Subnucleus $b$ of the c-MAO (ventrocaudal I0) & $\begin{array}{l}1-(\text { med }) / / 1-, 1-(\text { lat }) / a-/ / 2-, 2 a-/ / 3-, 2 b-/ / 4 b-, c-/ / \\
4 b-, d-/ / 5 a-, 3 b-/ / e 2-\text { (vermal and central negative compart- } \\
\text { ments) }\end{array}$ & $\begin{array}{l}\text { Somatosensory, vestibular, } \\
\text { mesodiencephalic }\end{array}$ \\
\hline IV & d-DA0, v-DA0, rostral and central DM (rostrodorsal I0) & $\begin{array}{l}2-/ / 4-, b+/ / f+, b-/ / f-, 3+/ / e 1+, 3-/ / e 1-,(3 b+/ / e 2+), 4-/ / \\
5-, 5-/ / 6-\text { (negative and lightly positive compartments in the hemi- } \\
\text { sphere and the rostral and caudal pars intermedia) }\end{array}$ & Somatosensory \\
\hline V & DC and VLO (dorsocaudal I0) & flocculus and lobule X (aldolase C-positive) & Visual \\
\hline
\end{tabular}

Refer to Sugihara and Shinoda (2004) for details. See the legend to Fig. 1 for abbreviations.

length of the cuneiform along its long axis was $\sim 500 \mu \mathrm{m}$, whereas its diameter perpendicular to the long axis was $\sim 200-300 \mu \mathrm{m}$. The direction of the long axis of the cuneiform was often toward the hilus of the $\mathrm{CN}$, which was located in the rostroventral corner of the $\mathrm{CN}$ (Fig. 2C and also see individual termination areas in subsequent figures). Retrogradely labeled neurons were occasionally seen within the termination area when the olivary injection of the tracer was larger (Fig. $2 B$, inset). These are presumably nucleo-olivary projecting neurons (Ruigrok and Voogd, 1990).

\section{Olivonuclear organization conformed to the five-group scheme}

We previously reported that the aldolase $\mathrm{C}$ compartments in the cerebellar cortex and the olivocerebellar projections to these compartments could be classified into five groups (groups I-V), based on clustering of the olivary origin of the topographic olivocerebellar projection to similar compartments (Table 1) (Sugihara and Shinoda, 2004). Areas of the IO belonging to each group receive rather specific inputs from several areas of the CNS, suggesting that these groups may correspond to the gross functional compartmentalization of the cerebellar system (Table 1).

To determine whether the olivonuclear projection also obeys this scheme, we sorted the $123 \mathrm{IO}$ injection cases into the five groups based on the compartment in which the labeled climbing fibers terminated as was done previously (Sugihara and Shinoda, 2004). The reconstructed nuclear termination areas labeled by all the 123 olivary injections were then plotted together in groupspecific colors (green, group I; blue, group II; yellow, group III; red, group IV; gray, V group) and viewed from different directions to examine the distribution of each group in the $\mathrm{CN}$ (Fig. $3 C)$.

Group IV areas (i.e., nuclear termination areas of olivocerebellar axons, the climbing fibers of which terminated in a group IV cortical compartment) (Fig. $3 \mathrm{Ca}, \mathrm{Cb}$, red) were best observed in rostral and dorsal views of the CN. Group IV areas included regions located in the dorsal portion of the LVN, the entire AIN (including the DLH), and the area between the AIN and LVN. These areas were continuous with one another and thus formed a single cluster.

Group III areas were best observed from the dorsal view (Fig. $3 C b$, yellow). Group III areas included the entire rostrodorsal surface of the FN, the DLP, the dorsal aspect of the ICG, and the dorsomedial PIN. These areas were continuous with each other and formed a single cluster that extended mediolaterally from the most medial FN to the PIN.
Most group II areas could be observed in the caudal view. Most were distributed in the caudal FN and ICG (Fig. $3 C c$, blue). These areas extended to the ventral FN between group I and III areas, as seen in the ventral view (Fig. $3 C d$, blue between green and yellow). The other group II areas were distributed laterally in the ventral PIN (Fig. 3Cc , blue, $C d$, blue curve). These two clusters nearly touched each other at the caudoventral junction between the PIN and ICG.

Group I areas could be observed with a ventral view (Fig. $3 C d$ ), in which the group II areas in the ventral PIN were removed for clarity. Group I areas were distributed in the ventral FN, ventral ICG, PIN, and DN (Fig. $3 C d$, green). These group I areas were continuously arranged from the most medial to the most lateral $\mathrm{CN}$. Group V areas were distributed in the ventral DN and in the adjacent dorsal Y nucleus (infracerebellar nucleus) (Fig. $3 C d$, gray), as reported previously (Sugihara et al., 2004).

In summary, the termination areas of each group were clustered in specific, non-overlapping portions of the CN. The clusters tended to be elongated transversely, mostly parallel to each other. Thus, our data suggest that the five-grouped organization, which was originally proposed with regard to aldolase $\mathrm{C}$ compartments and the olivocerebellar projection pattern in the cerebellar cortex, seem to be applicable to the $\mathrm{CN}$. Therefore, in the following sections, we will describe the detailed topographic organization of the olivonuclear projection in each group.

\section{Group I}

Cortical group I area has been defined as darkly labeled aldolase C-positive compartments that extend rostrally to the anterior lobe beyond the primary fissure $(1+/ / 1+, 2+/ / 3+, 4+/ / 5+$, $5+/ / 6+$, and $6+/ / 7+)$ in the cerebellar cortex (Fig. $3 B$, green). They are innervated by the ventrolateral parts of subdivisions of the IO [subnucleus $a$ of the caudal parts of the medial accessory olive (c-MAO); the rostral part of the medial accessory olive ( $\mathrm{r}$ $\mathrm{MAO}$ ); the ventral lamella of the principal olive (v-PO), except for the caudomedial part; and the dorsal lamella of the principal olive (d-PO)] (Fig. 3A, green) (Sugihara and Shinoda, 2004).

The caudal part of subnucleus $a$, the most lateral part of the c-MAO, which innervates $1+/ / 1+$ in lobules I-VI and VIII-IX in the cortex (Sugihara and Shinoda, 2004), projected to the most ventral part of the medial FN (Fig. $4 A$, red, yellow). The midcaudal (yellow-green, green) and central (blue, dark blue) parts of subnucleus $a$, which innervate medial and central $2+/ / 3+$ in lobules I-VIII in the cortex, respectively, projected to the most ventral parts of the central and lateral FN, respectively. The ros- 
tral parts of subnucleus $a$, which innervate lateral $2+/ / 3+$ in lobules I-VIII in the cortex, projected to the most ventral part of the ICG (purple, pink). Overall, the caudal to rostral sites in subnucleus $a$ of the c-MAO projected to medial to lateral sites in the ventral FN and ICG, respectively (Fig. $4 A$, black arrow).

The r-MAO (Fig. $4 B$ ), which innervates $4+/ / 5+$ in the cortex (Sugihara and Shinoda, 2004), projected to the PIN, except for the most ventral and medial PIN. The caudal (Fig. $4 B$, red, brown, orange, yellow), central (yellow-green, green, cyan, purple), and rostral (dark blue, magenta, pink) parts of the r-MAO projected to the PIN medially, centrally, and laterally, respectively. Furthermore, the lateral (red, cyan, dark blue, pink) and medial (yellow-green, purple, magenta) parts of the r-MAO projected to the PIN ventrally and dorsally, respectively. These projection patterns indicated a two-dimensional topographical relationship. The caudal (or caudolateral) to rostral (or rostromedial) sites in the r-MAO projected to the medial to lateral sites in the PIN, respectively (Fig. $4 B$, black arrow), whereas the medial (or caudomedial) to lateral (or rostrolateral) sites in the r-MAO projected to the dorsal to ventral sites in the PIN, respectively (Fig. $4 B$, white arrow).

The v-PO, except for its caudomedial portion (Fig. 4C), which innervates $5+/ / 6+$ in the cortex (Sugihara and Shinoda, 2004), projected to the caudal DN including the CP. The CP, which protrudes dorsocaudally between the PIN and $\mathrm{DN}$, has been conventionally considered to belong to the AIN (Voogd, 2004). However, the CP may be considered to belong to the $\mathrm{DN}$ because of this projection. The medial or caudomedial parts (Fig. 4C, red, yellow, pink) and lateral (cyan, blue, pink) parts of the $\mathrm{v}-\mathrm{PO}$ projected to the medial and lateral portions of the caudal DN, respectively. Furthermore, the caudolateral (pink, magenta) and rostromedial (yellow-green, cyan, yellow) parts of the $\mathrm{v}-\mathrm{PO}$ projected to the ventral and dorsal parts of the caudal $\mathrm{DN}$, respectively. This indicated a two-dimensional topographical relationship in the projection from the v-PO to the caudal DN. The medial to lateral sites in the $\mathrm{v}$-PO projected to the medial and lateral sites in the caudal DN, respectively (Fig. 4C, black arrow), whereas the rostral to caudal sites in the v-PO projected to the dorsal to ventral sites in the caudal DN, respectively (Fig. $4 C$, white arrow).

The d-PO (Fig. $4 D$ ), which innervates $6+/ / 7+$ in the cortex (Sugihara and Shinoda, 2004), innervated the DN, except for the caudal and most ventral parts (designated the "rostrolateral" DN). The rostrolateral (Fig. 4D, pink, red, brown, orange, yellow) and caudomedial (Fig. 4D, cyan, blue, yellow-green, green, pale green) parts of the d-PO projected to the lateral and rostral portions of the rostrolateral DN, respectively. Furthermore, the caudolateral (Fig. 4D, green, yellow-green, yellow) and rostromedial (Fig. 4D, magenta, brown, purple, dark blue) parts of the d-PO projected to the ventral and dorsal parts of the rostrolateral
C $\mathrm{CN}$
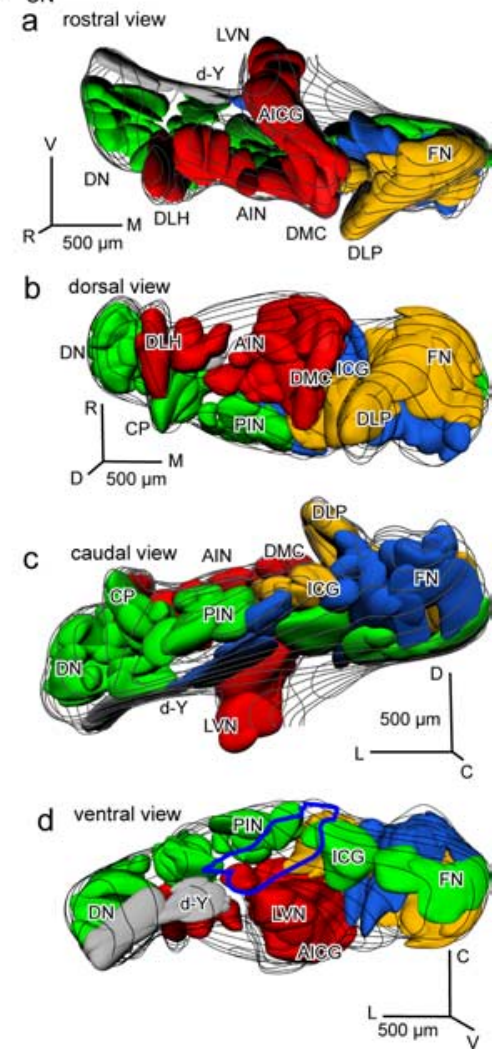

Figure 3. Clustering in the CN of termination areas of nuclear collaterals of the olivary projections sorted into five groups based Dorsal subnuclei were shifted to the right. $\boldsymbol{B}$, Mapping of labeled climbing fibers in aldolase $\boldsymbol{C}$ compartments on the unfolded cheme of the cerebellar cortex. Each injection was classified into one of five groups (see Results) based on its projection pattern areas $(C$ are indicated by different colors, depending on which group they belong to (green, group I; blue, group Il; yellow, group III; red, the $\mathrm{CN}$. Note that the mediolateral direction is consistent in all subpanels $(\boldsymbol{a}-\boldsymbol{d})$. In the ventral view $(\boldsymbol{d})$, terminations in the v-PIN that

DN, respectively. This indicated a two-dimensional topographical relationship in the projection from the d-PO to the rostrolateral DN. The rostrolateral to caudomedial sites in the d-PO projected to the caudal to rostral sites in the lateral $\mathrm{DN}$, respectively (Fig. 4D, black arrow), whereas the caudolateral and rostromedial sites in the d-PO projected to the ventral to dorsal sites in the rostrolateral DN, respectively (Fig. $4 D$, white arrow).

In summary, the topography of group I olivonuclear collaterals was highly correlated with the olivocortical topography. To describe the olivocerebellar topography within each group, a hypothetical sequential arrangement (designated "orientation axis") of olivary subareas has been proposed (Sugihara and Shinoda, 2004). In group I, the orientation axis (Fig. $4 E$, left, black arrows) runs from subnucleus $a$ of the MAO (caudal to rostral), through the r-MAO (caudal to rostral) and v-PO (medial to lateral), to the d-PO (lateral to medial), which corresponds to the mediolateral arrangement of the cortical compartments that belonged to group I (Sugihara and Shinoda, 2004). The present results indicate that this orientation axis corresponds to mediolateral arrangement of the $\mathrm{CN}$ group I areas (ventral FN, ventral ICG, lateral PIN, caudal DN, and then lateral DN) (Fig. $4 E$, right, black arrows). In addition to this mediolateral arrangement, a 


\section{Group I}
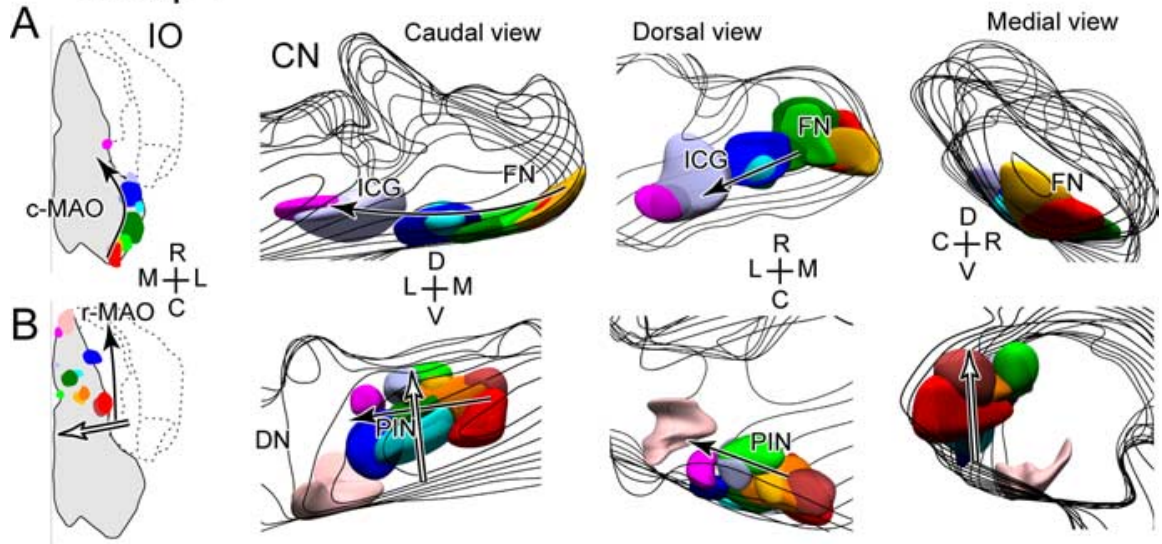

C
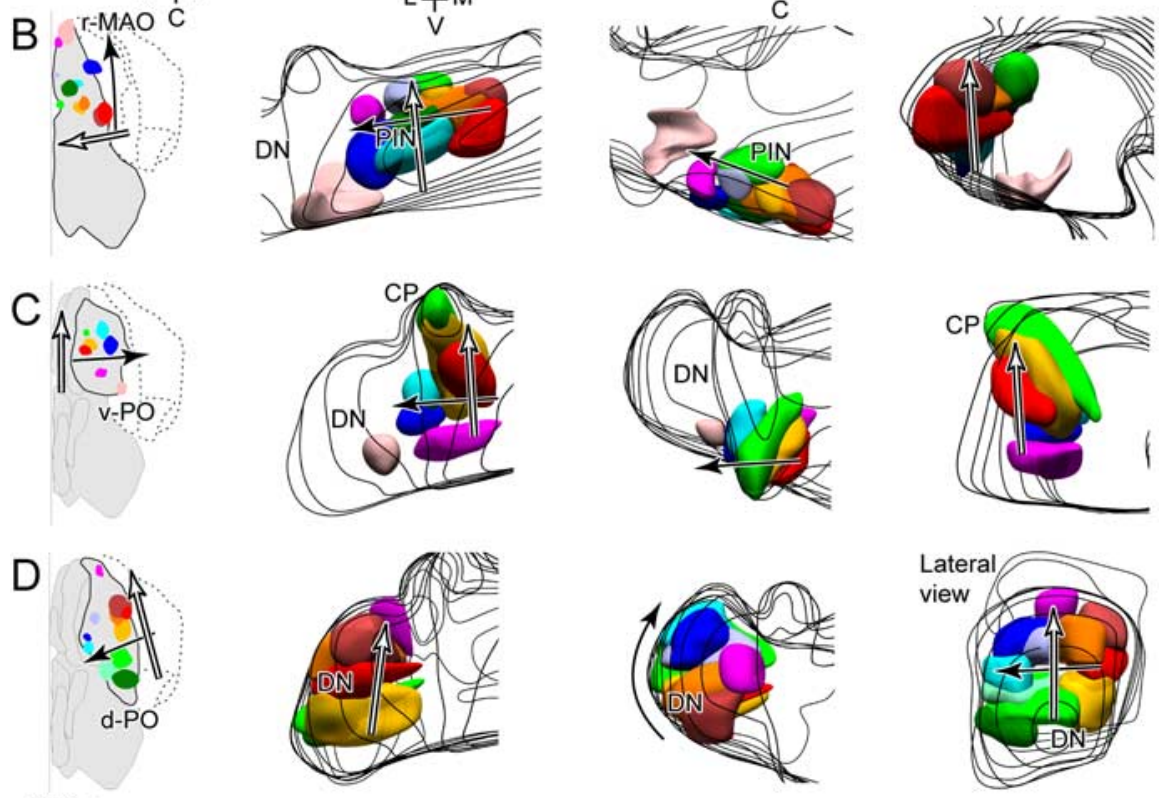

Midline

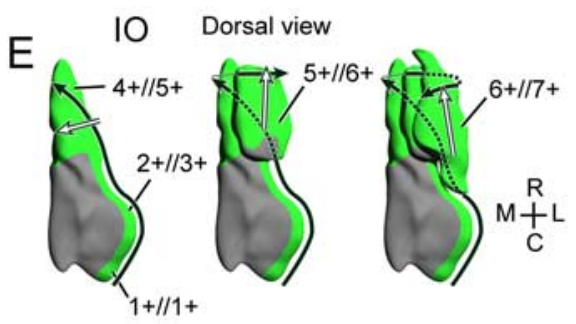

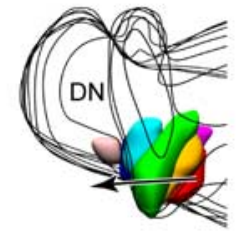
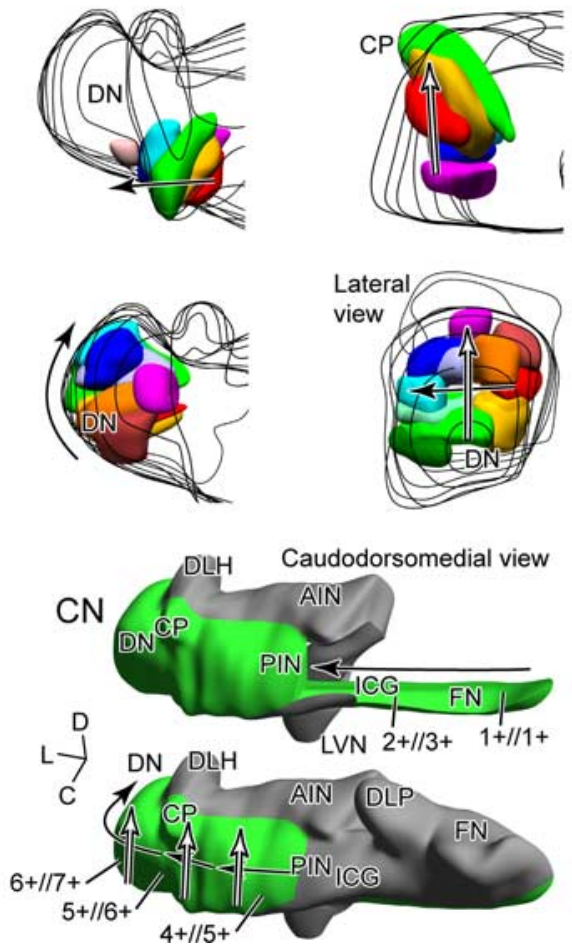

Figure 4. Olivonuclear projection pattern of group I. $A-D$, Three-dimensional mapping of nuclear termination areas of collaterals of olivocerebellar axons labeled by BDA injections in subnucleus $a$ of the c-MAO $(\boldsymbol{A} ; n=8$; specific colors for individual injections), the $\mathrm{r}-\mathrm{MAO}(\boldsymbol{B} ; n=11)$, the $\mathrm{v}-\mathrm{PO}(\boldsymbol{C} ; n=7)$, and the $\mathrm{d}-\mathrm{PO}(\boldsymbol{D} ; n=11)$. The leftmost subpanels show the injection sites in the dorsal view of the right 10 . The three subpanels on the right show caudal, dorsal, and medial (lateral for $\boldsymbol{D}$ ) views of the mapped termination areas depicted within the coronal, horizontal, or parasagittal contours of the nuclei (wire frames), respectively, at the same levels as where the termination areas were located. Olivocerebellar neurons in these areas were classified into group I, based on the injection sites in the olive and their distribution of labeled climbing fibers in the cortex (see Results for details). $\boldsymbol{E}$, Summary of the topographic olivonuclear projection of group I (as indicated with green) depicted in the solid scheme of the 10 (left) and the $\mathrm{CN}$ (right). Black and white arrows in $\boldsymbol{A}-\boldsymbol{E}$ indicate the primary and second orientation axes, respectively, to show topographic correspondence between the 10 and $C N$. The cortical aldolase $C$ compartments that the main axons of the depicted olivonuclear projection innervate are indicated as $1+/ / 1+$ and so on.

vertical arrangement could be defined in the PIN, caudal DN, and lateral $\mathrm{DN}$ based on the two-dimensional olivonuclear topography (see above paragraph) (Fig. $4 E$, white arrows).

\section{Group II}

Cortical group II area has been defined as darkly labeled aldolase C-positive compartments that do not extend rostrally beyond the primary fissure $(\mathrm{a}+/ / 2+, 2 \mathrm{~b}+/ / 4+, \mathrm{c}+/ / 4 \mathrm{~b}+$, and $\mathrm{d}+/ / 5 \mathrm{a}+)$ in the cerebellar cortex. They are innervated by several medial subnuclei and adjacent areas in the IO [subnucleus $c$ of the c-MAO, subnucleus $\beta$, dorsomedial cell column subnucleus (DMCC), caudal parts of the dorsomedial group of the $\mathrm{v}-\mathrm{PO}(\mathrm{DM})$, and caudomedial part of the v-PO] (Sugihara and Shinoda, 2004). Group II has been further divided into two subgroups in terms of the pattern of innervation by olivocerebellar axons [Sugihara and Shinoda (2004), their Fig. 8 A]. One subgroup (designated here IIa) includes $\mathrm{a}+/ / 2+$ in lobules VIa, VIII, and IX and $2 \mathrm{~b}+/ / 4+$, which were mainly innervated by the entire subnucleus $\beta$, the DMCC, caudal DM, and caudomedial v-PO. Caudal subnucleus $c$ is indistinguishable from caudal subnucleus $\beta$ cytologically (Ruigrok, 2004) and also in terms of the olivocerebellar projection pattern (Sugihara and Shinoda, 2004). Therefore, caudal subnucleus $c$ was included in caudal subnucleus $\beta$ in this study. The other subgroup (designated here IIb) includes $2+/ / \mathrm{a}+$ in lobules VIb-c and VII and $c+/ / 4 b+$ and $d+/ / 5 a+$, which were mainly innervated by medial and lateral subnucleus $c$ of the c-MAO (Table 1).

Concerning the nuclear projection of group IIa (Fig. $5 A$ ), subnucleus $\beta$ projected to the central and caudoventral FN and ventral ICG. This area is located dorsocaudal to the area innervated by group I (see above). Caudal subnucleus $\beta$ projected to the medial part of the caudoventral FN (Fig. 5A, red, brown, orange, yellow), whereas rostral subnucleus $\beta$ projected to the lateral part of the caudoventral FN and the ventral ICG (Fig. 5A, yellow-green, light green, green, cyan). This topography could be explained by the orientation axis that ran from caudal subnucleus $\beta$ to rostral subnucleus $\beta$ (Sugihara and Shinoda, 2004). This axis corresponded to the mediolateral direction in the termination areas of group IIa in the FN and ICG (Fig. 5A, black arrows).

Concerning the rest of group IIa (Fig. $5 B$ ), the DMCC (Fig. 5B, cyan, blue), caudal DM (purple, magenta), and caudomedial v-PO (salmon pink, pink), all of which innervate $2 b+/ / 4$ in the cortex, projected to the most ventral sheet-shaped area of the PIN. The projection areas of group IIa in the FN and ventral ICG and in the ventral PIN did not seem to simply be contiguous to each other but were intercalated by the projection area of group I. The topography within the projection to the ventral PIN was not so clear, although the DMCC, caudal DM, and caudomedial v-PO seemed to project to the ventral PIN more or less medially, centrally, and laterally, respectively. The orientation axis has been hypothesized to run from the DMCC, through the caudal DM, and to the caudomedial v-PO (Sugihara and Shinoda, 2004). This axis seemed to correspond to the mediolateral direction in the termination areas of group IIa in the ventral PIN (Fig. $5 A$, black arrows). 

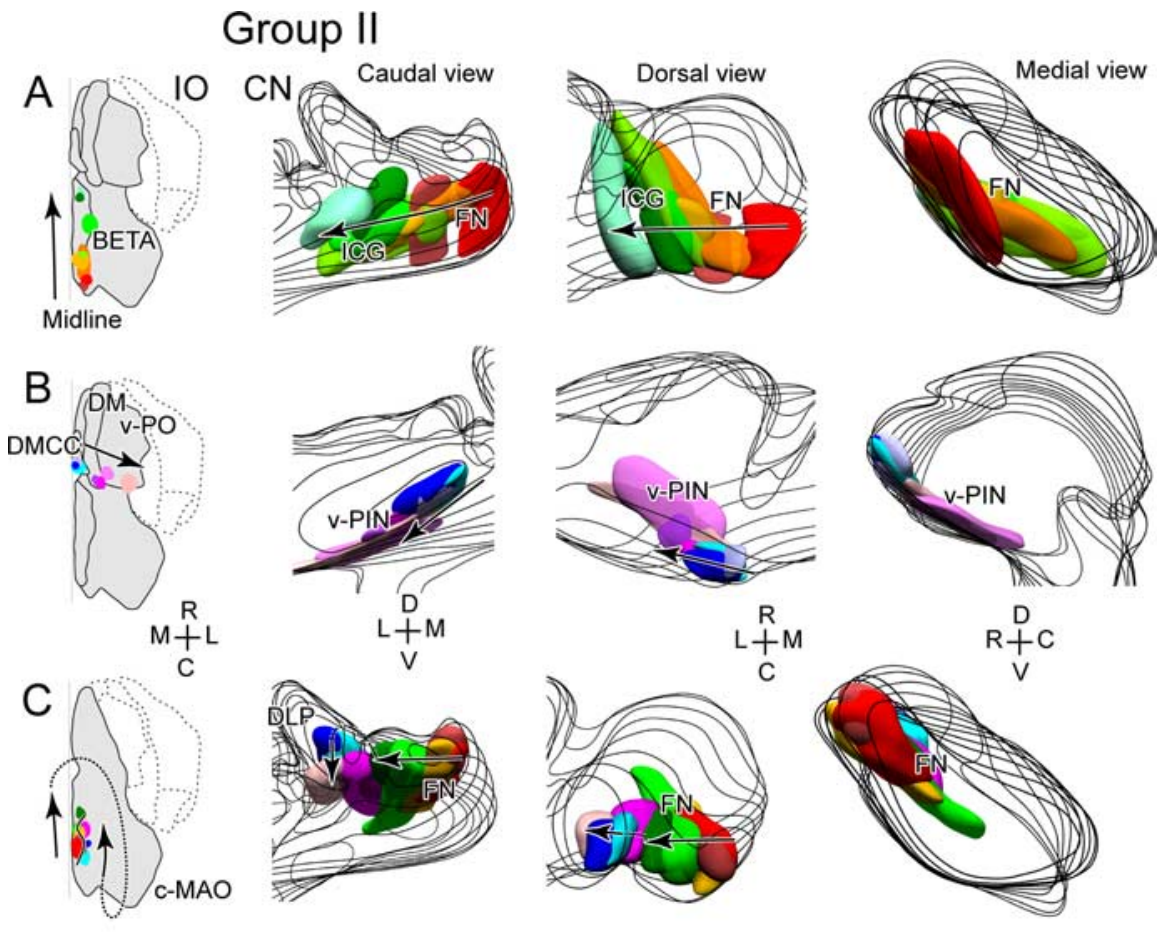

were aligned along distinct but parallel orientation axes. Group IIa areas were further subdivided into the FN (plus ICG) part and the ventral PIN part. For each subgroup, the caudorostral arrangement of IO regions mostly could be mapped to a mediolateral sequence of $\mathrm{CN}$ regions (Fig. $5 D$, black arrows).

\section{Group III}

Cortical group III has been defined as aldolase C-negative compartments in the vermis and the central pars intermedia [1-(med)//2-, $1-($ lat $) / \mathrm{a}-/ / 2-, 2 \mathrm{a}-/ /$ $3-, \quad 2 b-/ / 4 a-, \quad c-/ / 4 b-$, and $d-/ /$ $5 a-)]$. They are innervated by the central portion of the c-MAO (subnucleus $b$ ) (Sugihara and Shinoda, 2004). Based on its topographic projection pattern, subnucleus $b$ has been divided into lateral and medial parts, each of which was further subdivided into three to four areas rostrocaudally (Fig. 6C, left).

Concerning lateral subnucleus $b$ (Fig. $6 A$ ), its caudal part, which innervates cortical compartment $1-$ (med)//1-, projected to the rostrodorsal aldolase C-negative area of the most medial part of the FN (Sugihara and Shinoda, 2004). This projection pattern could be further subdivided into caudomedial and caudolateral areas. Caudolateral (Fig. 6A, red, brown, orange, yellow, green, dark green) and caudomedial (Fig. 6A, salmon, yellowgreen) areas of lateral subnucleus $b$ innervated $1-(\mathrm{med}) / / 1-$ in lobules VIa, VIII, and IX and lobules VIb-VIc and VII, respectively, and innervated more rostral and more dorsal parts of the medial rostrodorsal FN (Fig. 6A, caudal and dorsal views). In each projection, more rostral areas (Fig. 6A, yellow-green, green, darkgreen) innervated more lateral parts of 1 -(med)//1 - in the cortex and more lat-

Concerning the nuclear projection of group IIb, subnucleus $c$ innervated the central FN, dorsal to the area where group IIa projected (Fig. $5 C$ ). In the central FN, the caudal part of medial subnucleus $c$, which projects to the most medial area in lobules VIb-VIc and VII in the cortex, projected most medially (Fig. 5C, red, brown), and the rostral part of medial subnucleus $c$, which innervates $\mathrm{a}+/ / 2+$ in lobules VIb-VIc and VII in the cortex, projected more laterally (Fig. $5 C$, yellow, light green, green). The rostral and caudal parts of lateral subnucleus $c$, which mainly innervates $c+/ / 4 b+$ and $d+/ / 5 a+$ in the cortex, respectively, projected further laterally to the dorsal (Fig. 5C, cyan, blue) and ventral (Fig. 5C, magenta, pink) portions of the caudal neck of the DLP, respectively. The orientation axis ran in the caudorostral direction in medial and then lateral subnucleus $c$ in succession (Fig. 5C, leftmost panel) (Sugihara and Shinoda, 2004). This axis corresponded roughly to the mediolateral direction in the termination areas of group IIb in the FN (Fig. $5 C$, middle two panels).

In summary, the olivonuclear topography in group II could be primarily explained by assuming two subgroups (IIa and IIb) that eral parts of the medial rostrodorsal FN. The intermediate part of lateral subnucleus $b$, which innervates $1-($ lat $) / a-/ / 2-$ in the cortex, projected to the central and lateral parts of the rostrodorsal FN (Fig. 6A, blue, cyan, pale blue-green, lavender) and also weakly projected to the ventral portion of the LVN, the inferior vestibular nucleus, and nucleus X (data not shown). The rostral part of lateral subnucleus $b$, which innervates $2 \mathrm{a}-/ / 3-$ in the cortex, projected to the dorsal ICG (Fig. 6A, magenta, violet, pink). Thus, the caudorostral orientation axis in lateral subnucleus $b$ corresponded to the mediolateral direction in the rostrodorsal FN and the dorsal ICG (Fig. 6C, arrows in the yellow areas).

Concerning medial subnucleus $b$ (Fig. 6B), its caudolateral part, which innervates $2 b-/ / 4 a-$ in the cortex, projected to the rostral neck of the DLP (Fig. $6 B$, red, orange, brown, yellow). The caudomedial part of medial subnucleus $b$, which innervates $c-/ /$ $4 \mathrm{~b}-$ in the cortex, projected to the apex of the DLP (Fig. $6 B$, yellow-green, green, dark green). The intermediate part of medial subnucleus $b$, which innervates $\mathrm{d}-/ / 5 \mathrm{a}-$ in the cortex, projected 
to the caudal neck of the DLP close to the aldolase C-positive area (Fig. 6B, cyan, blue, dark blue). There was some degree of overlap among the above three nuclear projection areas. The rostral part of medial subnucleus $b$, which mainly innervates $3 \mathrm{~b}-/ / \mathrm{e} 2-$ in the cortex, projected to the dorsomedial area in the PIN (Fig. 6B, lavender, magenta, violet, pink). Thus, the caudorostral orientation axis in medial subnucleus $b$ corresponded to the mediolateral direction from the DLP to the dorsomedial PIN (Fig. 6C, arrows in the orange areas).

In summary, lateral and medial subnucleus $b$ mostly projected to the ventral and dorsal areas of a combination of the rostrodorsal FN, dorsal ICG, and dorsomedial PIN, respectively. In either projection, more rostral areas in subnucleus $b$ projected more laterally in the $\mathrm{CN}$.

\section{Group IV}

Cortical group IV has been defined as aldolase C-negative compartments and their neighboring lightly positive compartments in the rostral and caudal portions of pars intermedia $(2-/ / 4-, \mathrm{b}+/ / \mathrm{f}+, \mathrm{b}-/ /$ $\mathrm{f}-, 3+/ / \mathrm{e} 1+, 3-/ / \mathrm{e} 1-$, and putatively $3 \mathrm{~b}+/ / \mathrm{e} 2+)$ and all of the negative compartments in the hemisphere $(4-/ / 5-$ and $5-/ / 6-)$ of the cerebellar cortex. They are innervated by the dorsal subnuclei of the IO [ dorsal (d-DAO) and ventral (v-DAO) folds of the dorsal accessory olive and the central and rostral DM] (Sugihara and Shinoda, 2004).

The d-DAO (Fig. 7A), which innervates $2-/ / 4-$ in the cortex, projected to the dorsal portion of the LVN and the gray matter scattered in the hilar white matter between the LVN and the medial AIN (Fig. $7 A)$. These islands of gray matter were designated here as the anterior ICG (AICG), because they were located mostly anterior (rostral) to the ICG but also included the most rostral portion of the ICG [BuisseretDelmas et al. (1993), their Fig. 7, panel 6]. In contrast to other olivonuclear projections, the projection from the d-DAO to the LVN and AICG was not localized, but instead was rather broad. This conclusion was supported by the fact that the seven injections that were made in the $\mathrm{d}-\mathrm{DAO}$ were made into relatively distinct, non-overlapping regions of the d-DAO, and yet the termination areas in the LVN and AICG significantly overlapped between experiments (Fig. 7A). The densest termination was often seen in the AICG (five of seven cases) (Fig. 7A, bottom, red, green, cyan, blue, pink). In the two other cases (Fig. $7 A$, yellow, yellow-green), the absence was presumably attributable to only a small number of axons being labeled in these cases. In the mapping of the densest termination areas (Fig. $7 \mathrm{~A}$, bottom), there seemed to be a rough topography (Fig. $7 A$, black arrow): the medial (Fig. 7A, red, green) and lateral d-DAO (Fig. 7A, cyan, blue, pink) projected to the ventrolateral and dorsomedial AICG, respectively. There may be another axis in this topography, albeit not

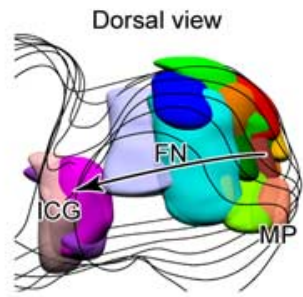

$$
\stackrel{\mathrm{R}}{\mathrm{L}}+\mathrm{M}
$$
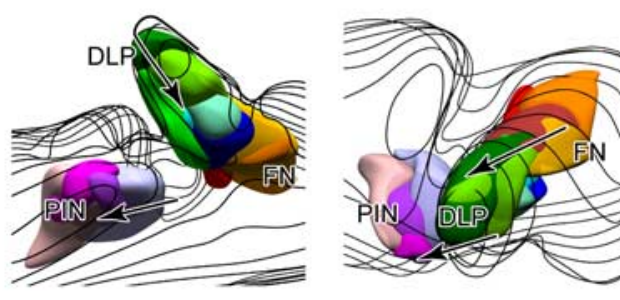

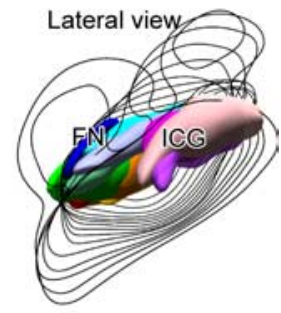

$\stackrel{\mathrm{D}}{\mathrm{R}} \mathrm{V}$

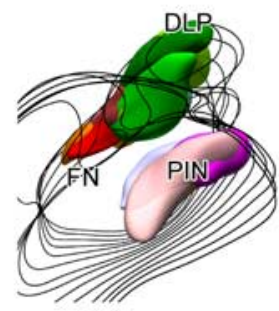

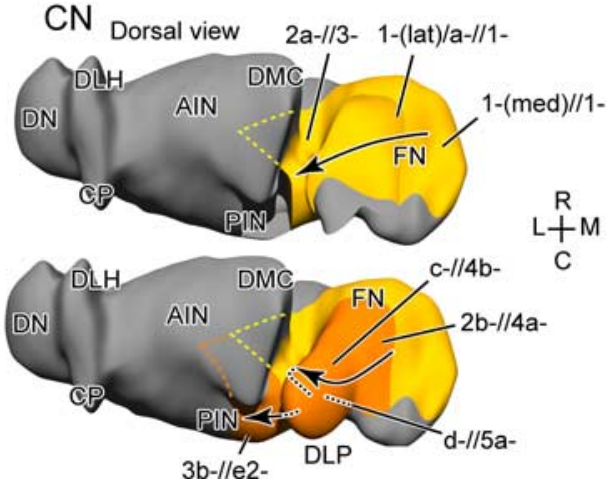

3b-//e2-

Figure 6. Olivonuclear projection pattern of group III. $\boldsymbol{A}-\boldsymbol{C}$ are depicted in the same format as in Figure 4. A, B, Threedimensional mapping of nuclear termination areas of collaterals of olivocerebellar axons labeled by BDA injections in lateral subnucleus $b$ of the $c-M A O(A ; n=14$; specific colors) and medial subnucleus $b$ of the $c-M A O(B ; n=14)$. $\boldsymbol{C}$, Summary of the (0) (left) and the CN (right). In the right top subpanel, the DLP and dorsomedial PIN (orange areas) were removed to show yellow areas. Dotted yellow and orange curves indicate lateral extension of yellow and orange areas underneath the AIN. Black arrows in $A-C$ show the orientation axis to indicate topographic correspondence between the 10 and $C N$.

very clear; the rostral d-DAO (Fig. 7A, green, pink) seemed to project to the more rostral areas in the AICG (Fig. $7 A$, white arrow).

It has been suggested that the lateral pole of the d-DAO innervates mainly $\mathrm{b}+/ / \mathrm{f}+$ in the cortex (Sugihara and Shinoda, 2004). This innervation could not be further clarified in the present study. However, based on one case in which the injection covered both the lateral pole of the d-DAO and the v-DAO and innervated both $\mathrm{b}+/ / \mathrm{f}+$ and $3+/ / \mathrm{e} 1+$ (data not shown), the lateral pole of the d-DAO seemed to project to the caudomedial AICG that was located rostroventral to the caudal half of the most medial AIN that was innervated by the collaterals of axons innervating $3+/ / \mathrm{e} 1+$.

The caudolateral v-DAO (Fig. 7B), which mainly innervates $3+/ / e 1+$ in the cortex (Sugihara and Shinoda, 2004), projected to the caudal half of the most medial AIN (i.e., the DMC of the AIN) (Fig. 7B, yellow-green, green, pale blue-green). The lateral $\mathrm{v}$-DAO, which was found to innervate mainly $\mathrm{b}-/ / \mathrm{f}-$ in the cortex in the preparations in this study, projected to the rostral half of the most medial AIN (Fig. $7 B$, red, brown, yellow). The 


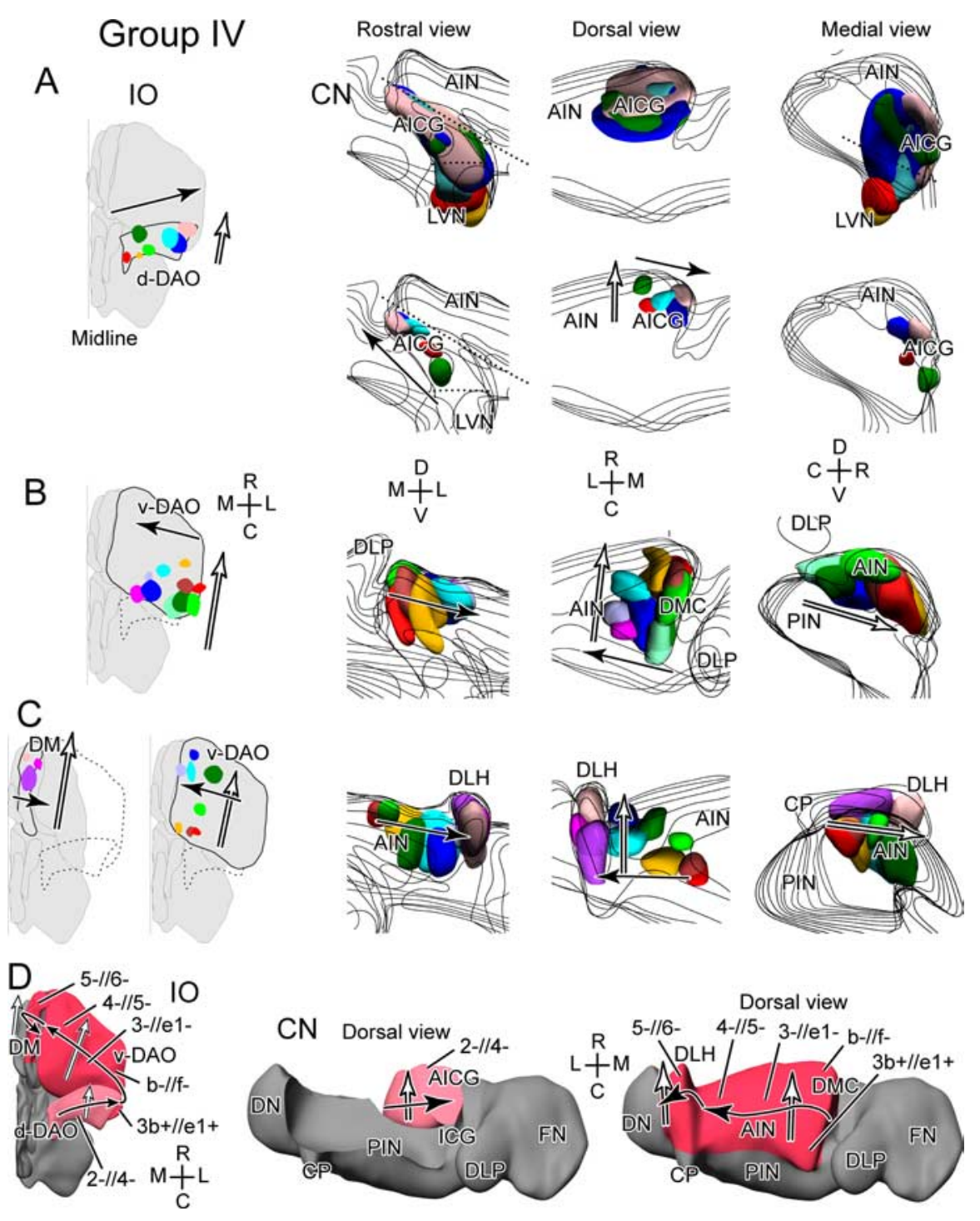

Figure 7. Olivonuclear projection pattern of group IV. $\boldsymbol{A}-\boldsymbol{D}$ are depicted in the same format as in Figure 4. $\boldsymbol{A}-\boldsymbol{C}$, Threedimensional mapping of nuclear termination areas of collaterals of olivocerebellar axons labeled by BDA injections in the d-DAO $(\boldsymbol{A} ; n=7$; specific colors), the caudal and lateral v-DAO $(\boldsymbol{B} ; n=10)$, the rostral and medial v-DA0 and the central and rostral DM $(\boldsymbol{C} ; n=11)$. In $\boldsymbol{A}$, the entire termination areas are depicted in the top part. The densest distribution of the terminals was often seen in the junction between the AIN and the LVN, designated here AICG. Areas of the densest termination in the AICG are depicted in the bottom part. D, Summary of the topographic olivonuclear projection of group IV (as indicated with pink and red; pink, from d-DAO to LVN and AICG; red, from v-DAO to AIN and DM) depicted in the solid scheme of the I0 (left) and the CN (right). Black and white arrows in $\boldsymbol{A}-\boldsymbol{D}$ show the primary and second orientation axes, respectively, to indicate topographic correspondence between the 10 and $C N$.

central v-DAO, which mainly innervates $3-/ / \mathrm{e} 1-$ in the cortex (Sugihara and Shinoda, 2004), projected to the central AIN (Fig. $7 B$, cyan, blue, violet, magenta; $C$, red, brown, yellow, yellowgreen). The medial part of the v-DAO, which mainly innervates $4-/ / 5-$, projected to the lateral part of the AIN (Fig. 7C, green, cyan, blue, violet). The more rostral part of the medial v-DAO projected to the more rostral part in the AIN (Fig. 7C, blue, green). The central and rostral DM, which innervates $5-/ / 6-$ in the cortex, projected to the DLH (Fig. 7C, purple, magenta, pink). The more rostral DM projected to the more rostral DLH (Fig. 7C, pink).

The projections described above indicated that a twodimensional topography was consistently observed throughout the projection from the v-DAO (and DM) to the AIN (Fig. 7 B, C, black and white arrows). The more caudolateral and rostrome- dial $\mathrm{v}$-DAO projected to the more medial and lateral AIN, respectively (Fig. $7 B$, light-green, green, red, and so on; $C$, blue, cyan, purple), whereas the more rostrolateral and caudomedial v-DAO innervates the more rostral (Fig. $7 B$, red, brown, yellow; $C$, green, blue) and caudal (Fig. $7 B$, cyan, blue, pink; $C$, red, brown, yellow, blue) AIN, respectively. The topographic projection from the central and rostral DM to the DLH could be simply understood by extending the topographic projection from the v-DAO to the AIN.

In summary, the topography of the group IV was characterized by assuming two orientation axes (Sugihara and Shinoda, 2004). The primary axis, which runs from the d-DAO (medial to lateral), through the v-DAO (caudolateral to rostromedial), to the DM (Fig. 7D, black arrows), corresponded to the mediolateral arrangement in the cortex in terms of olivocortical topography (Sugihara and Shinoda, 2004). This axis corresponds to a dorsomedial direction in the AICG and to the mediolateral direction in the AIN (Fig. $7 D$, black arrows). The second orientation axis was defined to lie roughly in the caudorostral direction, perpendicular to the main axis, in the d-DAO, v-DAO, and DM. This axis mostly corresponded to the rostrocaudal direction in the AICG and AIN (Fig. 7D, white arrows). The projection to the LVN from the d-DAO was broad, with no clear topography. We could not identify either the origin of the projection to $3 \mathrm{~b}+/ / \mathrm{e} 2+$ or the nuclear termination by collaterals of this innervation. It seemed possible that it originated from somewhere in the central v-DAO that was not covered in our injections.

\section{Group V}

Cortical group $\mathrm{V}$ area has been defined as the flocculus and nodulus in the cerebellar cortex, which are innervated by the dorsal cap subnucleus and ventrolateral outgrowth subnucleus (Sugihara et al., 2004; Sugihara and Shinoda, 2004). The nuclear collaterals of olivocerebellar axons of this group project to the ventral DN and the dorsal Y nucleus (infracerebellar nucleus) (Sugihara et al., 2004). The same nuclear projections as reported previously were seen in the samples obtained in the present study $(n=5)$ (Fig. $3 A$, gray). However, an orientation axis was not determined in this group (Fig. 3Cd).

\section{Compartmentalization of the entire $\mathrm{CN}$ and its correspondence to the aldolase $\mathrm{C}$ expression pattern in the $\mathrm{CN}$}

To understand how the $\mathrm{CN}$ are divided into the termination areas of the five groups, three-dimensional schemes of the termination areas of each group (Figs. 4-7, bottom panels) were assembled into a single model of the $\mathrm{CN}$, which was then cut at several 
parasagittal and coronal planes to show schematic parasagittal and coronal sections with group organization indicated by colors (Fig. 8). The schematic sections in Figure 8 were obtained roughly at the same levels as the photomicrographs of stained sections in Figure 1. Comparison of Figure $1, A$ and $B$, and Figure $8, A$ and $B$, indicated that the termination areas of groups I (green), II (blue and cyan), and V (gray) are located in an aldolase C-positive caudoventral part of the $\mathrm{CN}$ and those of groups III (yellow and orange) and IV (red and pink) are located in an aldolase C-negative rostrodorsal part of the CN. Indeed, such a relationship was noticed during mapping of nuclear termination areas in individual experiments, because brain sections were double labeled for BDA and aldolase $\mathrm{C}$. The correspondence of termination areas of groups I, II, and V with aldolase C-positive areas was directly shown by comparing dorsocaudal views of the three-dimensional displays of these areas (Fig. 9). The correspondence between the five groups and aldolase $\mathrm{C}$ expression in the $\mathrm{CN}$ was consistent with that in the cerebellar cortex, because groups I, II, and $\mathrm{V}$ also occupied aldolase C-positive compartments in the cerebellar cortex (Sugihara and Shinoda, 2004).

Concerning the FN, the group I area was located most ventrally (Fig. $8 A a, A b, B b$, green), and the group IIa area was located next most ventrally (Fig. $8 \mathrm{Aa}-$ $A c, B a-B d$, cyan). The group IIb area was located in the dorsocaudal FN (Fig. $8 A a, A b, B a, B b$, blue). These areas (groups I, IIa, and IIb) were aldolase $C$ positive. Group III areas (Fig. $8 A a-A c, B a-$ $B d$, yellow, orange) occupied the rostrodorsal portion and the DLP of the FN, which were aldolase $C$ negative. Concerning the ICG, the group I area was located in the ventral part of the ICG (Fig. $8 A c, B a, B b$, green), and the group III area was located in the dorsal part of the ICG (Fig. $8 A c, B a, B b$, yellow).

The entire AIN, including the DLH, belonged to group IV (Fig. $8 A c-A f, B b-B d$, red) and was generally aldolase $\mathrm{C}$ negative, although the DMC had a slightly higher level of aldolase $C$ labeling. In the PIN, group III was located in the aldolase C-negative dorsomedial portion (Fig. $8 A d, B a, B b$, orange), and group IIa was located in the medial and rostral part of the most ventral portion (Fig. $8 A d, A e, B a, B b$, cyan). The rest of the PIN belonged to group I (Fig. $8 A d, A e, B a, B b$, green). Group IIa and I areas were aldolase $\mathrm{C}$ positive in the PIN. The entire $\mathrm{DN}$, which was aldolase $\mathrm{C}$ positive, belonged to group I (Fig. $8 A f, A g, B b-B d$, green), except for the most ventral and rostral portion, which belonged to group $\mathrm{V}$ (Fig. $8 A f, A g, B b, B c$, gray). The $\mathrm{CP}$, which was aldolase $\mathrm{C}$ positive, belonged to group I (Fig. $8 A f, B a$, green). This finding further supported the notion that the $\mathrm{CP}$ belongs to the $\mathrm{DN}$ but not to the DLH or AIN.

The AICG and LVN, which were generally aldolase C negative, belonged to group IV (Fig. $8 A d, B c, B d$, pink). The dorsal Y nucleus (infracerebellar nucleus), which was aldolase $C$ positive, belonged to group $\mathrm{V}$ (Fig. $8 A e, B c$, gray).
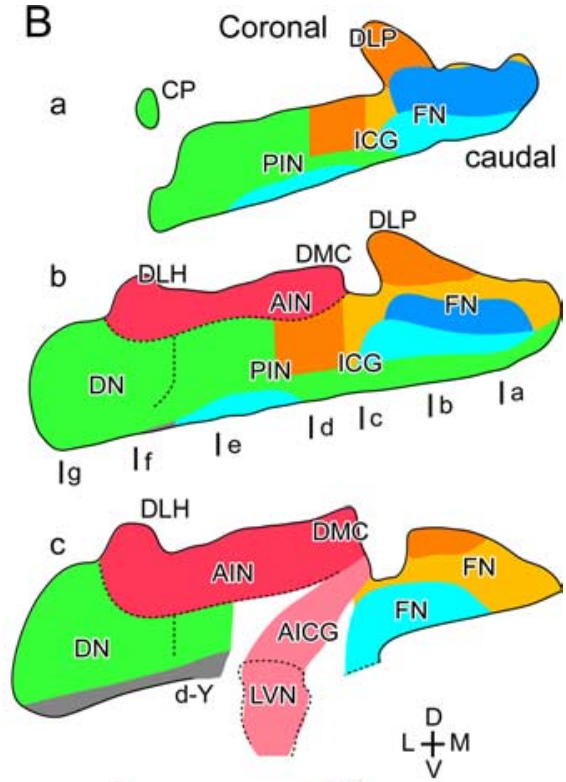

Group I (green)

Group II (blue)

Group III (yellow)

Group IV (red)

Group V (gray)

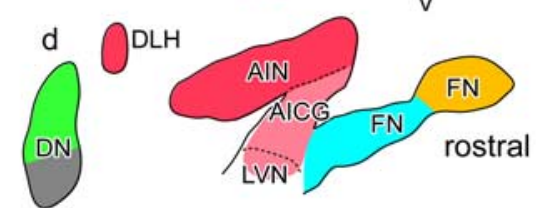

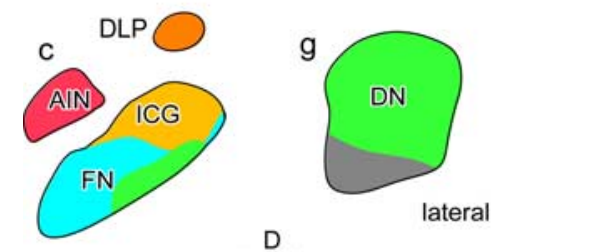

Figure 8. Schematic summary of compartmentalization of the CN shown in parasagittal ( $\boldsymbol{A} \boldsymbol{a}-\boldsymbol{A g}$, medial to lateral) and coronal (Ba-Bd, caudal to rostral) sections of the left CN. Vertical bars in $\boldsymbol{B} \boldsymbol{b}(\boldsymbol{a}-\boldsymbol{g})$ indicate approximate locations of parasagittal sections roughly correspond to the photomicrographs of aldolase Clabeling in the CN shown in Figure 1. Comparison of the corresponding sections in Figure 1 and this figure indicates that termination areas of groups I, II, and V generally belong to the aldolase C-positive

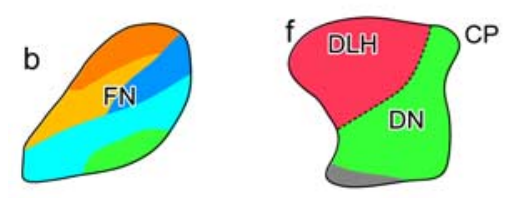

A Parasagittal

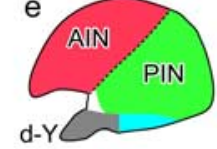

lateral

\section{.}

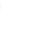
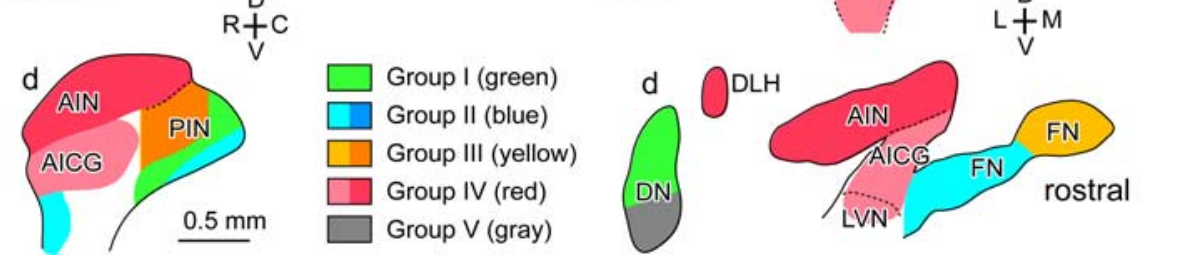

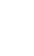
part of the $\mathrm{CN}$ and those of groups III and IV belong to the aldolase C-negative part.

\section{Cytoarchitecture of the nuclear termination areas}

Different parts of the $\mathrm{CN}$ differ with regard to the size and density of neurons (Voogd, 2004). Differences in cytoarchitecture suggest different properties and projections. Therefore, the cytoarchitecture of the termination areas of the olivonuclear projections that belonged to each of the five groups was examined. Only the characteristics of the most obvious type of neurons were described here (Table 2).

Group I areas contained medium-sized neurons in the ventral FN and ICG and large or middle-sized round neurons in the dorsal PIN and DN (Table 2). Group II areas contained small to medium-sized neurons, which were round or polygonal in the caudoventral FN and round or fusiform in the ventral PIN. The entire group III area in the rostrodorsal FN, dorsal ICG, and dorsomedial PIN contained large polygonal neurons. Cytoarchitecture in group IV areas showed more variation than in other areas. Group V areas contained small to middle-sized round or fusiform neurons.

Overall, areas belonging to the same group sometimes showed, although not always, similar cytoarchitecture across different subnuclei. Furthermore, the borders between groups within the FN, ICG, PIN, and DN tended to coincide with the borders between areas with different cytoarchitecture. Specifically, the rostrodorsal "shell-shaped area" of the FN with large neurons (Voogd, 2004) corresponded with group III. The PIN and $\mathrm{DN}$ have been subdivided into the dorsal magnocellular part and the ventral parvocellular part (Voogd, 2004), which corresponded to group I and groups II and V, respectively. These 

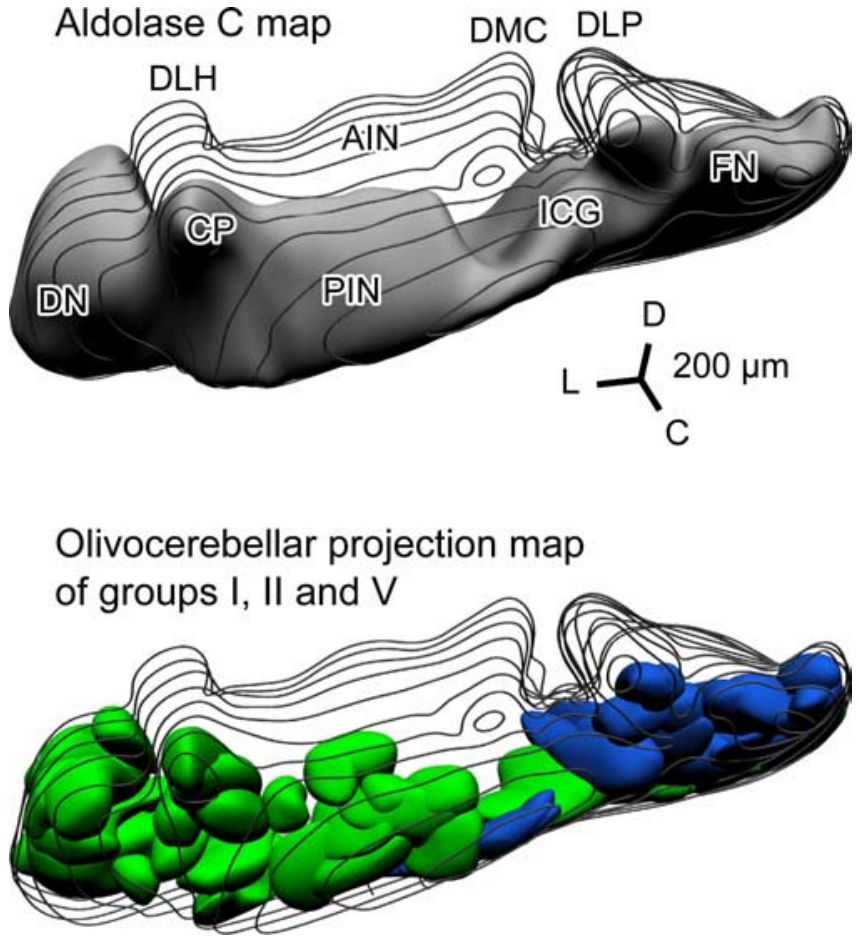

Figure 9. Three-dimensional reconstruction of the aldolase (-positive area (top) and termination areas of olivonuclear projections (bottom) that belong to groups I (green), II (blue), and $\mathrm{V}$ in the left $\mathrm{CN}$ shown in a dorsocaudal view for comparison. The wire frames are coronal contours of the CN. Group V termination areas are mostly hidden under group I areas in this view.

findings indicated a certain relationship between the groups and the cytoarchitecture in the $\mathrm{CN}$.

\section{Topographic olivonuclear organization across the groups in} the FN

The organization of the $\mathrm{CN}$ as a whole and the orientation axes of the olivonuclear projection are summarized in Figure 10 and compared with the organization of the cerebellar cortex and the IO that was reported previously (Sugihara and Shinoda, 2004). The areas that belong to different groups are distinctly colored consistently throughout the $\mathrm{IO}$, the $\mathrm{CN}$, and the cerebellar cortex (Fig. 10) (green, group I; blue and cyan, group II; yellow and orange, group III; red and pink, group IV; gray, group V).

In the AIN and dorsal main portions of the PIN and DN, which belonged to either group I or IV, the olivocerebellar topography was clearly organized in two-dimensional space. In contrast, the entire FN and ICG were divided into groups I-III and showed no comparable two-dimensionally organized topography. However, some topographic organization could be discerned across groups involved in the projection from the c-MAO to the FN and ICG. In the c-MAO, subnucleus $a$ (green, group I), lateral subnucleus $b$ (yellow, group III), medial subnucleus $b$ (orange, group III), and subnucleus $c$ (blue, group IIb) are located from the lateral to medial portions (Fig. $10 A b, D a$, gray arrow). Subnucleus $\beta$ and caudal subnucleus $c$ (cyan, group IIa) are then located dorsocaudally to medial subnucleus $c$. The above consecutive subareas of the c-MAO projected to different subareas in the FN, which were aligned sequentially from the ventral FN (green, group I), through the rostrodorsal FN (yellow, group III), the DLP (orange, group III), and the caudal neck of the DLP and the caudal FN (blue, group IIb), to the caudoventral FN (cyan, group IIa), as shown by the gray arrow in Figure $10 \mathrm{Db}$. These findings indicated that the positional arrangement of groups was preserved in the projection from the c-MAO to the FN.

\section{Discussion}

Compartmental organization of the $\mathrm{CN}$ compared with that of the cerebellar cortex and the IO

The present study clarified the aldolase $\mathrm{C}$ expression pattern in the $\mathrm{CN}$ and the topographic olivonuclear projection pattern. The olivonuclear projection pattern conformed to the five-group scheme that was originally proposed for the olivocortical projection (Sugihara and Shinoda, 2004). Both in the cortex and CN, groups I, II, and V were correlated with aldolase C-positive Purkinje cells (somata and terminals, respectively). This finding is compatible with the idea that the entire cerebellar system is formed by the parallel assembly of an olivo-cortico-nuclear microcomplex or modules (Ito, 1984; Apps and Garwicz, 2005). In this module, an olivary neuron projects to Purkinje cells, and such Purkinje cells terminate on nuclear neurons that receive input from the same olivary neuron via its axon collaterals. To further prove the presence of such modules, we require more information about the details of Purkinje cell projections. As to the positional organization of the aldolase $\mathrm{C}$ expression pattern in the cortex and nuclei, aldolase C-positive and -negative compartments are intercalated with each other to form stripes in the cerebellar cortex, whereas the $\mathrm{CN}$ had only two distinct compartments, one aldolase C-positive caudoventral part and the other aldolase C-negative rostrodorsal part. Furthermore, the nuclear areas that receive collateral projections of olivocerebellar axons in each of the five groups form a single cluster that crosses traditional nuclear borders. In contrast, cortical areas that belong to each group are separated into multiple stripes in the cortex (Sugihara and Shinoda, 2004). Thus, the positional compartmental organizations in the cerebellar cortex and CN were significantly different from each other.

As to the topographic organization of five groups, the present results revealed that there was a simple one area-to-one area relationship throughout the topographic olivonuclear projection. However, the olivo-cortical projection has a one area-to-multiple areas relationship, because single olivocerebellar axons often innervate the rostral and caudal cerebellum within the same longitudinal band (Sugihara et al., 2001). The positional arrangements among subareas that belonged to each group in the IO were well preserved in the $\mathrm{CN}$, as indicated by orientation axes (Figs. 4-7). Furthermore, the positional arrangements of different groups seen in the c-MAO were preserved in the FN (Fig. 10). These results indicate that the topographic organization of the five groups in the $\mathrm{CN}$ is significantly consistent with that in the IO. This consistency of nuclear and olivary topographic organizations enable us to consider some area-dependent differences in their organizations. The two orientation axes that were evident in the olivonuclear projection to some parts of the $\mathrm{CN}$ suggest that the origin (v-DAO, d-DAO, r-MAO, and v- and d-PO) and target (AIN, AICG, PIN except for the ventral and medial parts, and DN except for the ventral part) of these projections are organized into topographically similar two-dimensional sheets. Indeed, the $\mathrm{v}-\mathrm{DAO}$, d-DAO, r-MAO, and v- and d-PO are lamella shaped (Ruigrok, 2004), and the DN looks like a curly sheet in the primate (Chan-Palay, 1976). However, two-orientation axes were not clear in the olivonuclear projection to other parts of the $\mathrm{CN}$, although a different topographic organization across groups was seen in the olivonuclear projection from the c-MAO to the FN and ICG. Therefore, different parts of the CN might have different structural organizations or differentiations. 
Table 2. Major olivocortical and olivonuclear topographic projection pattern in the rat

\begin{tabular}{|c|c|c|c|c|c|c|c|c|}
\hline \multirow[b]{2}{*}{ Group } & \multicolumn{3}{|l|}{ Inferior olive } & \multicolumn{2}{|l|}{ Cerebellar cortex } & \multicolumn{3}{|l|}{ Cerebellar nuclei } \\
\hline & Subnucleus & Subareas & & Aldolase $\mathrm{C}^{a}$ & $\begin{array}{l}\text { Zone } \\
\text { (module) }^{b}\end{array}$ & Subarea & Cytoarchitecture $^{c}$ & $\begin{array}{l}\text { Ruigrok and } \\
\text { Voogd's } \\
\text { case }^{d}\end{array}$ \\
\hline \multirow[t]{5}{*}{ I } & Subnucleus $a$ & Caudal & & $\begin{array}{l}1+/ / 1+ \\
2+/ / 3+\text { (medial }\end{array}$ & $A$ & FN, ventral (medial) & Small/mid-size, & $547 R$ \\
\hline & & Rostral & & $2+/ / 3+$ (lateral) & $A(A X)$ & ICG, ventral & & Part of $439 R$ \\
\hline & r-MAO & & & $4+/ / 5+$ & $\mathrm{C} 2$ & PIN, dorsolateral & $\begin{array}{l}\text { Large, round, } \\
\text { moderately or } \\
\text { densely packed }\end{array}$ & $\begin{array}{l}548 \mathrm{R}, 205 \\
\text { part of } 46\end{array}$ \\
\hline & $\mathrm{v}-\mathrm{PO}$ & & & $5+/ / 6+$ & D1 & DN, caudal & & Part of $259 \mathrm{R}$ \\
\hline & d-P0 & & & $6+/ / 7+$ & D2 & DN, rostrolateral & & $480 \mathrm{R}, 255,245 \mathrm{~L}$ \\
\hline \multicolumn{9}{|r|}{ - } \\
\hline \multirow[t]{2}{*}{ Ila } & $\beta$ & Caudal $^{e}$ & & $\begin{array}{c}\mathrm{a}+/ / 2+\text { (medial) } \\
(\mathrm{Vla}, \mathrm{VIII}, \mathrm{IX})\end{array}$ & A & $\begin{array}{l}\text { FN, ventrocaudal } \\
\text { (medial) }\end{array}$ & $\begin{array}{l}\text { Small/mid-size, } \\
\text { round/polygonal }\end{array}$ & $\begin{array}{l}\text { Part of 118, } \\
\text { part of } 408 \mathrm{~L}\end{array}$ \\
\hline & & Central and rostral & & $\begin{array}{c}\mathrm{a}+/ / 2+\text { (lateral) } \\
\quad(\mathrm{Vla}, \mathrm{VIII}, \mathrm{IX})\end{array}$ & A & $\begin{array}{l}\mathrm{FN} \text {, ventrocaudal } \\
\text { (lateral) }\end{array}$ & & Part of $408 \mathrm{~L}, 72 \mathrm{~L}$ \\
\hline \multirow[t]{3}{*}{$\mathrm{llb}$} & Subnucleus & Medial & & $a+/ / 2+,(V l b-V I I)$ & A & FN, midcaudal (medial) & & Part of 118 \\
\hline & & Lateral & Caudal & $c+/ / 4 b+$ & Lateral A & FN, midcaudal (dorsolateral) & & \\
\hline & & & Rostral & $d+/ / 5 a+$ & Lateral A & FN, midcaudal (lateral) & & \\
\hline Ila & \multicolumn{3}{|c|}{ DMCC, caudal DM, caudomedial v-P0 } & $2 b+/ / 4+$ & $X-C X$ & PIN, ventral & $\begin{array}{l}\text { Small/mid-size, } \\
\text { round/fusiform }\end{array}$ & Part of $440 R$ \\
\hline \multirow[t]{7}{*}{ III } & \multirow[t]{7}{*}{$\begin{array}{l}\text { Subnucleus } b \\
\text { (cMA0) }\end{array}$} & \multirow[t]{3}{*}{ Lateral } & Caudal & $1-(\mathrm{med}) / / 1-$ & A & $\begin{array}{l}\text { FN, rostrodorsal } \\
\text { (medial) }\end{array}$ & Large, polygonal & $559 \mathrm{R}$ \\
\hline & & & Intermediate & $1-$ (lat)/a-//2- & $A(A 1)$ & FN, rostrodorsal (lateral) & & \\
\hline & & & Rostral & $2 a-1 / 3-$ & $\mathrm{x}$ & ICG, dorsal & & Part of 439R \\
\hline & & \multirow[t]{4}{*}{ Medial } & Caudolateral & $2 b-/ / 4 a-$ & Lateral A & DLP, rostral & & Part of 116 \\
\hline & & & Caudomedial & $c-/ / 4 b-$ & Lateral A & DLP, dorsal & & Part of 116 \\
\hline & & & Intermediate & $d-/ / 5 a-$ & Lateral A & DLP, central & & 66 \\
\hline & & & Rostral & $3 b-1 / e 2-$ & $C X$ & PIN, dorsomedial & & Part of 46 \\
\hline \multirow[t]{7}{*}{ IV } & \multirow[t]{2}{*}{ d-DAO } & \multicolumn{2}{|l|}{ Medial and central } & $2-/ / 4-$ & B & LVN and AICG & $\begin{array}{l}\text { Very large, polygonal, } \\
\text { sparsely packed (LVN); } \\
\text { polygonal, small (AICG) }\end{array}$ & $\begin{array}{l}\text { Part of } 192 \mathrm{R}, \\
\quad 189,188 \mathrm{R}, 480 \mathrm{~L}, 415 \mathrm{R}\end{array}$ \\
\hline & & \multicolumn{2}{|l|}{ Lateral pole } & $b+/ / f+$ & & & & \\
\hline & \multirow[t]{4}{*}{$\mathrm{v}-\mathrm{DAO}$} & \multirow{2}{*}{\multicolumn{2}{|c|}{$\begin{array}{l}\text { Caudolateral } \\
\text { Lateral }\end{array}$}} & $3+/ / \mathrm{e} 1+$ & C1 & DMC (caudomedial AIN) & Small, polygonal & Part of $459 \mathrm{R}$ \\
\hline & & & & $b-/ / f-$ & C1 & AIN, rostromedial & & \\
\hline & & \multirow{2}{*}{\multicolumn{2}{|c|}{$\begin{array}{l}\text { Central } \\
\text { Rostromedial }\end{array}$}} & $3-/ / e 1-$ & C1 & AIN, central & Mid-size, polygonal, & $547 \mathrm{~L}$ \\
\hline & & & & $4-1 / 5-$ & C3 & AIN, lateral & & $559 \mathrm{~L}$ \\
\hline & DM & \multicolumn{2}{|l|}{ Central and rostral } & $5-1 / 6-$ & Do & DLH & $\begin{array}{l}\text { Mid-size/large, } \\
\text { polygonal }\end{array}$ & $\begin{array}{l}\text { Part of 75R, } \\
\quad 440 \mathrm{~L}, 202,415 \mathrm{~L}\end{array}$ \\
\hline V & & \multicolumn{2}{|l|}{$D C$ and VLO } & \multicolumn{2}{|l|}{$\begin{array}{l}\text { Flocculus and } \\
\text { nodulus }^{f}\end{array}$} & $v-D N$ and $d-Y$ & $\begin{array}{l}\text { Small/mid-size, } \\
\text { round/fusiform }\end{array}$ & Part of 192R, 209 \\
\hline
\end{tabular}

See the legend to Fig. 1 for abbreviations.

${ }^{a}$ Aldolase ( compartment as a major termination area (Sugihara and Shinoda, 2004). See Results for details.

${ }^{b}$ Voogd and Bigaré, 1980; Buisseret-Delmas and Angaut, 1993; Voogd et al., 2003; Voogd and Ruigrok, 2004; Sugihara and Shinoda, 2004.

In this column, the density of neurons was "moderately packed" unless specified otherwise.

${ }^{d}$ Cases reported by Ruigrok and Voogd (2000) with nearly equivalent projection.

${ }^{e}$ Including caudal subnucleus $C$.

fSugihara et al., 2004.

\section{Relationship between the five groups and modules A-D in the $\mathrm{CN}$}

Previous studies have revealed rough schemes of olivonuclear (Ruigrok and Voogd, 2000), corticonuclear (Buisseret-Delmas and Angaut, 1993), nucleo-olivary (Ruigrok and Voogd, 1990), and nucleofugal (Teune et al., 2000) topographies and sorted the $\mathrm{CN}$, as well as the cerebellar cortex and the IO, into modules A-D. Specifically, Ruigrok and Voogd (2000) labeled and mapped olivonuclear projections by anterograde labeling of olivary neurons, as in the present study, and Pijpers et al. (2005) recently detailed them in module C. The projection patterns we found in the present study are compatible with their results (Table 2). However, the present study, with a larger number of cases of small in- jections and with three-dimensional mapping, revealed a more comprehensive and systematic compartmentalization of the $\mathrm{CN}$. Consequently, we could sort virtually all parts of the $\mathrm{CN}$ into five groups and determine their correspondence to modules A-D (Table 2).

The entire FN belongs to module $A$ in the conventional scheme, and further subdivisions of the FN have not been made before. The present study classified the compartmentalization of the FN into rostrodorsal group III, caudal group II (IIa and IIb), and small ventral group I areas. These compartments seem to be related to functional distinctions (see below).

The ICG, the area between the ventral FN and PIN, has been thought to belong to module X (Yatim et al., 1995). The present result indicated 


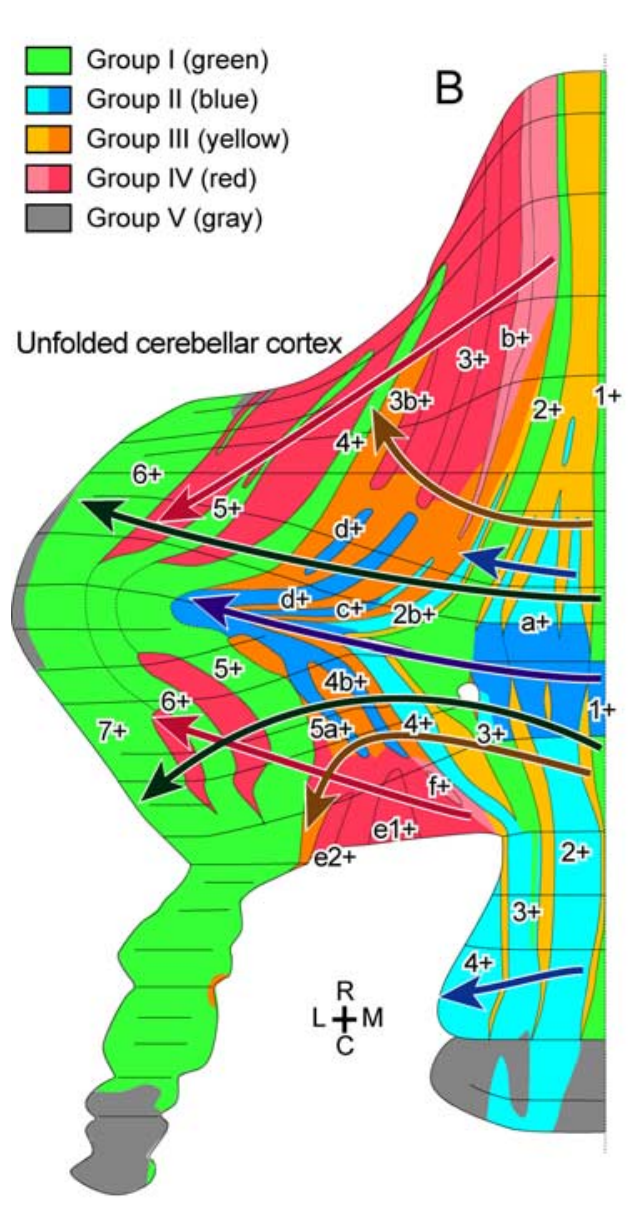

A
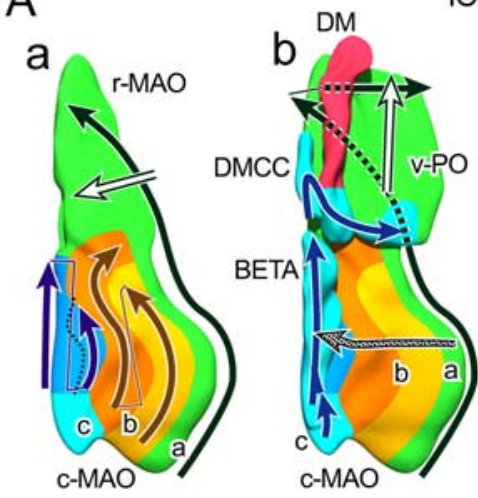

10, dorsal view
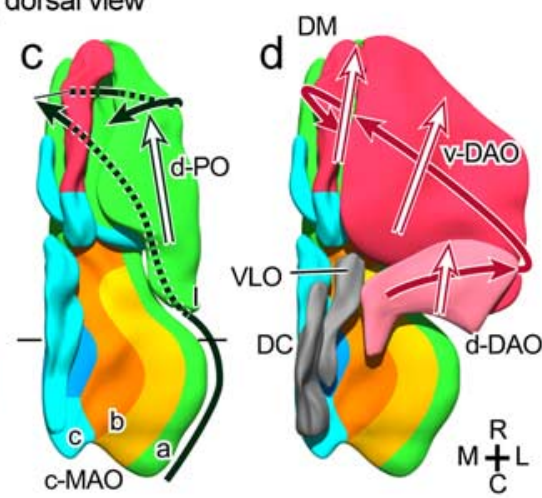

C

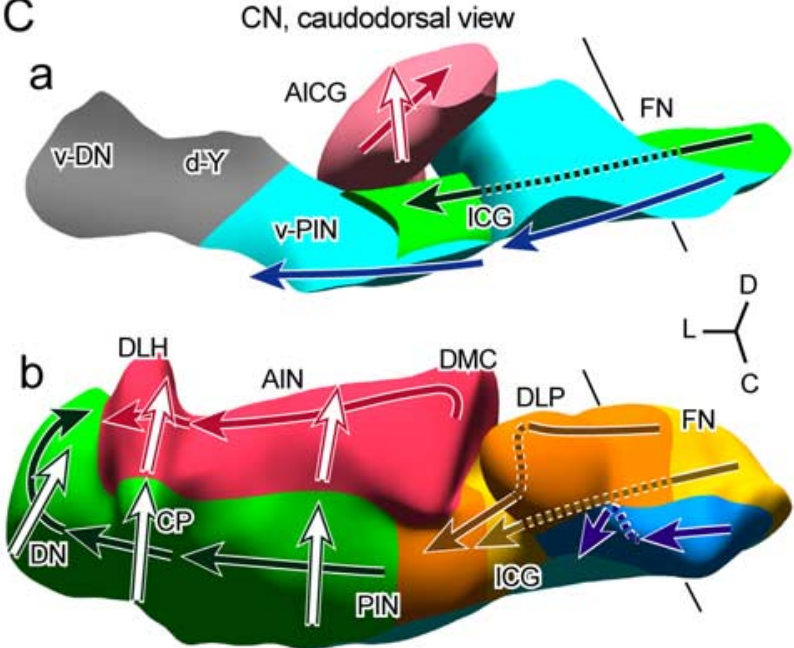

$\mathrm{D}$

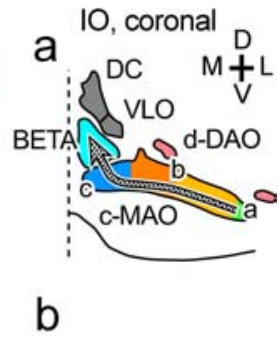

$\mathrm{CN}$, parasagittal

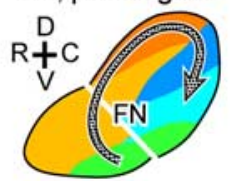

Figure 10. Schematics of the topography of five group-based compartmental organization of the right 10 , left cerebellar cortex, and left $C N$ of the rat. $A$, Subnuclei of the right $I 0$ in a dorsal view. In subpanels $\boldsymbol{a}-\boldsymbol{c}$, some subnuclei that are located more dorsally were omitted to show more ventral subnuclei $(\boldsymbol{a}, \mathrm{MAO} ; \boldsymbol{b}, \mathrm{MA0}, \mathrm{v}-\mathrm{PO}, \mathrm{DM}, \mathrm{DMCC}, \mathrm{BETA} ; \boldsymbol{c}, \mathrm{MAO}, \mathrm{v}-\mathrm{PO}, \mathrm{DM}, \mathrm{DMCC}, \mathrm{BETA}, \mathrm{d}-\mathrm{P0} ; \boldsymbol{d}$, the entire 10). $\boldsymbol{B}$, Unfolded left cerebellar cortex. The group organization here is basically the same as in our previous report (Sugihara and Shinoda, 2004), but groups II-IV are subdivided based on the data obtained in this study. C, Three-dimensional schemes of the ventral $(\boldsymbol{a})$ and whole $\mathrm{CN}(\boldsymbol{b})$. The scheme of the ventral $\mathrm{CN}$ is viewed from the same direction but depicts only group I in the FN and ICG, group Ila, group IV in the LVN and AICG, and group V. The colors that indicate groups (green, group I; cyan, group Ila; blue, group Ilb; yellow and orange, group III; red and pink, group IV) in this figure are consistent with those in the bottom panels of Figures $4-7$ and 8 . Colored arrows indicate the primary orientation axis in each group. White arrows indicate the second orientation axis recognized in some areas. $\boldsymbol{D}$, Topography across groups in the projection from the c-MAO to the FN. A coronal section of the c-MAO $(\boldsymbol{a})$ at the level indicated by transverse lines in $A \boldsymbol{c}$ and a combined parasagittal section of the $F N(\boldsymbol{b})$ at the level indicated by semivertical lines in $\boldsymbol{C} \boldsymbol{a}$, and $\boldsymbol{C} \boldsymbol{b}$ are shown. Gray (hatched) arrows in $\boldsymbol{D} \boldsymbol{a}, \boldsymbol{D} \boldsymbol{b}$, and $\boldsymbol{A} \boldsymbol{b}$ show the topographic relationship across groups in the projection from the c-MAO to the FN.

that the ICG could be further subdivided into dorsal aldolase C-negative and ventral aldolase C-positive parts. The ventral and dorsal ICG were innervated by collaterals of olivocerebellar axons that originate from adjacent parts of the c-MAO and project to adjacent but different aldolase $C$ compartments in the cerebellar cortex $(2+/ / 3+$ and $2 a-/ / 3-$ ), respectively (Table 2 ). Because $2+/ / 3+$ and $2 a-/ / 3-$ are regarded as modules AX and X, respectively (Voogd and Ruigrok, 2004; Sugihara and Shinoda, 2004), the ventral ICG may be regarded as module AX, whereas the dorsal ICG is compatible with module X.

The PIN is generally thought to belong to module C2. However, whether the medial part of the PIN includes the area that belongs to $\mathrm{C} 1$ has not been clarified by previous studies (Buisseret-Delmas and Angaut, 1993). The present results clearly addressed this issue. The dorsomedial PIN (group III) is aldolase C negative and belongs to module CX, the ventral PIN (group II) is aldolase C positive and belongs to module $\mathrm{X}$-CX, and the rest of the PIN (group I) is aldolase C positive and belongs to module C2 (Table 2).

The LVN, AIN (except the DLH), and DLH belong to modules B, $\mathrm{C} 1 / \mathrm{C} 3$, and D0, respectively. Because their corresponding olivocortical projections share some similarities, they have been considered to belong to group IV as a whole (Sugihara and Shinoda, 2004). Consistent with this grouping, the AIN and DLH, respective targets of the v-DAO and $\mathrm{DM}$, were found to be highly homogeneous with regard to the olivonuclear organization in the present study. Besides the LVN, the AICG was identified as the main target of the d-DAO in the present study. A previous study also mapped d-DAO projection to the area that was named AICG here (Pijpers et al., 2005). The present result suggests that the AICG may be regarded as equivalent to the $\mathrm{CN}$ in terms of its receiving a precise and topographic olivonuclear projection. However, the projection to the LVN from the d-DAO seems special among olivonuclear projections, because the olivonuclear projection to the LVN was broad and lacked a precise topography.

The DN belongs to module D. The D1 and D2 submodules have been thought to occupy the caudoventral and rostrodorsal DN, respectively (Teune et al., 2000). The present results were mostly compatible with this previous classification. The CP protrudes to the dorsocaudal aspects of the junction between the DN and PIN and is conventionally regarded as a part of the DLH [Voogd (2004), compare Figs. 2 and 7]. This area should be regarded as part of the DN (submodule D1), be- 
cause it was aldolase $\mathrm{C}$ positive and was innervated by axons that innervated 5+//6+ compartments belonging to group I.

Our previous classification that the dorsal Y nucleus belongs to the CN (Sugihara et al., 2004) is still valid in view of the present results. It constitutes group $\mathrm{V}$ together with the rostroventral parvocellular part of the DN.

\section{Functional aspects of the nuclear compartments}

We have proposed that each of the five groups in the olivocerebellar system influences a different aspect of motor control. This proposal is based on the observation that each group in the IO receives a unique set of inputs (Table 2) (Sugihara and Shinoda, 2004). In short, groups I-V may be primarily concerned with motor control that uses cerebral and mesodiencephalic (group I), vestibular (group IIa) and collicular (group IIb), somatosensory plus mesodiencephalic and vestibular (group III), somatosensory (group IV), and visual (group V) information, respectively. Our results suggest that we can extend our group hypothesis to the $\mathrm{CN}$. That is, each compartment identified in the $\mathrm{CN}$ is proposed to be involved in the same function that has been proposed for its corresponding olivocerebellar group. To give an example, different functions such as control of locomotion (Mori et al., 1999), saccade and other eye movements (Ohtsuka and Noda, 1991), and posture and head orientation (Wilden et al., 2002) have been reported in the FN. The subdivisions of the FN into the rostrodorsal aldolase C-negative part (group III-spinal), centrodorsocaudal part (group IIb-collicular), and centrocaudal part (group IIa-vestibular) in the present study may be directly related to the above functions (locomotion, eye movements, and head orientation). As to the nucleofugal projections from the $\mathrm{FN}$, it has been reported that the caudal FN, which essentially belongs to group II (vestibular and collicular), projects to the vestibular nucleus, but the rostral FN (group III in the present study) does not (Lee et al., 1989; Kurimoto et al., 1995; Teune et al., 2000). Similarly, grouping all of the $\mathrm{CN}$ compartments according to this scheme may be a way to split the $\mathrm{CN}$ into functionally distinct motor regions. Therefore, the nuclear compartmentalization defined in the present study may reflect a closer relationship to specific functional divisions of the $\mathrm{CN}$ with regard to motor control than do the traditional nuclear subdivisions (fastigial, interposed, and dentate nuclei).

\section{References}

Ahn AH, Dziennis S, Hawkes R, Herrup K (1994) The cloning of zebrin II reveals its identity with aldolase C. Development 120:2081-2090.

Apps R, Garwicz M (2005) Anatomical and physiological foundations of cerebellar information processing. Nat Rev Neurosci 6:297-311.

Brochu G, Maler L, Hawkes R (1990) Zebrin II: a polypeptide antigen expressed selectively by Purkinje cells reveals compartments in rat and fish cerebellum. J Comp Neurol 291:538-552.

Brodal A (1981) Neurological anatomy in relation to clinical medicine, Ed 3. New York: Oxford UP.

Buisseret-Delmas C, Angaut P (1993) The cerebellar olivocorticonuclear connections in the rat. Prog Neurobiol 40:63-87.

Buisseret-Delmas C, Yatim N, Buisseret P, Angaut P (1993) The X zone and CX subzone of the cerebellum in the rat. Neurosci Res 16:195-207.

Buisseret-Delmas C, Angaut P, Compoint C, Diagne M, Buisseret P (1998) Brainstem efferents from the interface between the nucleus medialis and the nucleus interpositus in the rat. J Comp Neurol 402:264-275.

Chan-Palay V (1976) Cerebellar dentate nucleus, organization, cytology and transmitters. Berlin: Springer.

Groenewegen HJ, Voogd J (1977) The parasagittal zonation within the olivocerebellar projection. I. Climbing fiber distribution in the vermis of the cat cerebellum. J Comp Neurol 174:417-488.

Hawkes R, Leclerc N (1987) Antigenic map of the rat cerebellar cortex: the distribution of parasagittal bands as revealed by monoclonal antiPurkinje cell antibody mobA113. J Comp Neurol 256:29-41.

Ito M (1984) The cerebellum and neural control. New York: Raven.

Kurimoto Y, Kawaguchi S, Murata M (1995) Cerebellotectal projection in the rat: anterograde and retrograde WGA-HRP study of individual cerebellar nuclei. Neurosci Res 22:57-71.

Lee HS, Kosinski RJ, Mihailoff GA (1989) Collateral branches of cerebellopontine axons reach the thalamus, superior colliculus, or inferior olive: a double-fluorescence and combined fluorescence-horseradish peroxidase study in the rat. Neuroscience 28:725-734.

Mori S, Matsui T, Kuze B, Asanome M, Nakajima K, Matsuyama K (1999) Stimulation of a restricted region in the midline cerebellar white matter evokes coordinated quadrupedal locomotion in the decerebrate cat. J Neurophysiol 82:290-300.

Ohtsuka K, Noda H (1991) Saccadic burst neurons in the oculomotor region of the fastigial nucleus of macaque monkeys. J Neurophysiol 65:1422-1434.

Pijpers A, Voogd J, Ruigrok TJH (2005) Topography of olivo-corticonuclear modules in the intermediate cerebellum of the rat. J Comp Neurol 492:193-213.

Pijpers A, Apps R, Pardoe J, Voogd J, Ruigrok TJH (2006) Precise spatial relationships between mossy fibers and climbing fibers in rat cerebellar cortical zones. J Neurosci 26:12067-12080.

Ruigrok TJ, Voogd J (1990) Cerebellar nucleo-olivary projections in the rat: an anterograde tracing study with Phaseolus vulgaris-leucoagglutinin (PHA-L). J Comp Neurol 298:315-333.

Ruigrok TJH (2004) Precerebellar nuclei and red nucleus. In: The rat nervous system, Ed 3 (Paxinos G, ed), pp 167-204. Amsterdam: Elsevier Academic.

Ruigrok TJH, Voogd J (2000) Organization of projections from the inferior olive to the cerebellar nuclei in the rat. J Comp Neurol 426:209-228.

Sugihara I, Shinoda Y (2004) Molecular, topographic, and functional organization of the cerebellar cortex: a study with combined aldolase $\mathrm{C}$ and olivocerebellar labeling. J Neurosci 24:8771-8785.

Sugihara I, Wu H-S, Shinoda Y (1999) Morphology of single olivocerebellar axons labeled with biotinylated dextran amine in the rat. J Comp Neurol 414:131-148.

Sugihara I, Wu H-S, Shinoda Y (2001) The entire trajectories of single olivocerebellar axons in the cerebellar cortex and their contribution to cerebellar compartmentalization. J Neurosci 21:7715-7723.

Sugihara I, Ebata S, Shinoda Y (2004) Functional compartmentalization in the flocculus and the ventral dentate and dorsal group y nuclei: An analysis of single olivocerebellar axonal morphology. J Comp Neurol 470:113-133.

Teune TM, van der Burg J, van der Moer J, Voogd J, Ruigrok TJH (2000) Topography of cerebellar nuclear projections to the brain stem in the rat. Prog Brain Res 124:141-172.

Voogd J (1967) Comparative aspects of the structure and fibre connexions of the mammalian cerebellum. In: Progress in brain research, Vol 25, The cerebellum (Fox CA, Snider RS, eds), pp 94-135. Amsterdam: Elsevier.

Voogd J (2004) Cerebellum. In: The rat nervous system, Ed 3 (Paxinos G, ed), pp 205-242. Amsterdam: Elsevier Academic.

Voogd J, Bigaré F (1980) Topographical distribution of olivary and cortico nuclear fibers in the cerebellum: a review. In: The inferior olivary nucleus. Anatomy and physiology (Courville J, de Montigny C, Lamarre Y, eds), pp 207-234. New York: Raven.

Voogd J, Ruigrok TJH (2004) The organization of the corticonuclear and olivocerebellar climbing fiber projections to the rat cerebellar vermis: The congruence of projection zones and the zebrin pattern. J Neurocytol 33:5-21.

Voogd J, Pardoe J, Ruigrok TJH, Apps R (2003) The distribution of climbing and mossy fiber collateral branches from the copula pyramidis and the paramedian lobule: congruence of climbing fiber cortical zones and the pattern of zebrin banding within the rat cerebellum. J Neurosci 23:4645-4656.

Wilden A, Glasauer S, Kleine JF, Büttner U (2002) Modelling transfer characteristics of vestibular neurons in the fastigial nucleus of the behaving monkey on the basis of canal-otolith interaction. NeuroReport 13:799-804.

Yatim N, Compoint C, Buisseret P, Angaut P, Buisseret-Delmas C (1995) On the caudal extension of the $\mathrm{X}$ zone in the cerebellar cortex of the rat. Neurosci Res 23:223-227. 